\title{
Hydroxide ions amplified by water entanglement underly the mechanism of general anesthesia
}

\author{
Hao Qian ${ }^{1} \dagger, \mathrm{Na} \mathrm{Li}^{1} \dagger$, Lei Yang ${ }^{1} \dagger$, Younian $\mathrm{Xu}^{1} \dagger$, Rong Chen ${ }^{1}$, Dongshi Lu ${ }^{1}$, Ruihan \\ Zhao ${ }^{1}$, Hui Liu $^{2}$, Nanxue Cui ${ }^{1}$, Qiao Zhou ${ }^{1}$, Shihai Zhang ${ }^{1}$ * \\ ${ }^{1}$ Department of Anesthesiology, Union Hospital, Tongji Medical College, Huazhong \\ University of Science and Technology, Wuhan, Hubei Province, 430000, China \\ ${ }^{2}$ Department of Pharmacology, School of Basic Medicine, Tongji Medical College, \\ Huazhong University of Science and Technology, Wuhan, Hubei Province, 430000, \\ China \\ *Corresponding author. Email: zhv@ hust.edu.cn \\ $\dagger$ These authors contributed equally to this work.
}

\begin{abstract}
It is believed that inhaled anesthetics occupy hydrophobic pockets within target proteins, but how inhaled anesthetics with diverse shapes and sizes fit into highly structurally selective pockets is unknown. For hydroxide ions are hydrophobic, we determined whether hydroxide ions could bridge inhaled anesthetics and protein pockets. We found that small additional load of cerebral hydroxide ions decreases anesthetic potency. Multiple-water entanglement network, derived from Ising model, has a great ability to amplify ultralow changes in the cerebral hydroxide ion concentration, and consequently, amplified hydroxide ions account for neural excitability. Molecular dynamics simulations showed that inhaled anesthetics produce anesthesia by attenuating the formation of multiple-water entanglement network. This work suggests amplified hydroxide ions underlying a unified mechanism for the anesthetic action of inhaled anesthetics.
\end{abstract}

General anesthesia is indispensable. Millions of surgical procedures and invasive examinations are performed under general anesthesia each year. General anesthesia is also fascinating because general anesthesia has been alluded to be an experimental inroad to consciousness $(1-4)$ which is perhaps the biggest mystery in nature, based on the facts that general anesthesia, a reversibly drug-induced unconscious state, is definable and anesthetic potency is quantifiable. Although general anesthesia is both indispensable and fascinating, the mechanism of action of inhaled anesthetics (IAs) remains obscure over 170 years $(5,6)$. The challenge, largely in part, is what property a host of molecules with highly diverse chemical structures can possibly have in common that causes general anesthesia (2). Since at the fundamental level all things are quantum, quantum processing may remove the diversities in chemical structure specific to individual anesthetics. Quantum properties may thus provide a corollary answer to unify diverse IAs into a common quantum-processing mechanism of anesthetic action $(3,7)$. Indeed, the notion that the element hosting consciousness must have a nuclear spin of $\frac{1}{2}$ has been proposed (8), based on the fact that singlets formed by $I=\frac{1}{2}$ nuclei are long-lasting because they are immune to the electric fields that neurons produce in the brain. This proposal has been confirmed, albeit indirectly, by our previous experiment (3) on the isotopic dependence of xenon anesthesia: ${ }^{129}$ xenon $\left(I=\frac{1}{2}\right)$ is less potent than xenon isotopes with zero nuclear spin, strongly indicating that the nuclear-spin property of ${ }^{129}$ xenon partly antagonizes its anesthetic property, suggesting a quantum-processing effect.

How is the nuclear spin involved in the anesthetic action of xenon anesthesia, 
and could quantum processing be extended from xenon to all IAs? If there exists a component in the brain that accounts for neural excitability through quantum processing with nuclear spins, these questions are answered, as IAs inhibit neural excitability by reducing this component explicitly as general anesthesia. As such, the candidate component must have three properties-crucial importance in all living organisms (9), nuclear spin or total nuclear spin of $\frac{1}{2}$, and a size small enough to exert quantum effects. Phosphorus and hydrogen are the only two biologically prevalent light elements with $I=\frac{1}{2}$. Phosphorus has been experimentally ruled out (10), leaving hydrogen as the only candidate. In living systems, most hydrogens are within water molecules. The importance of liquid water for the existence of life on Earth is undeniable. The water dissociation reaction, $2 \mathrm{H}_{2} \mathrm{O} \rightarrow \mathrm{H}_{3} \mathrm{O}^{+}+\mathrm{OH}^{-}$, generates a pair of hydronium $\left(\mathrm{H}_{3} \mathrm{O}^{+}\right)$and hydroxide $\left(\mathrm{OH}^{-}\right)$ions, both having total nuclear spins of $\frac{1}{2}$, both small enough to exert quantum effects, and both populating biochemistry. Using the $50 \%$ effective dose for loss of righting reflex (LORR $\mathrm{ED}_{50}$ ) for mice to sevoflurane as a measure, we report here that cerebral $\mathrm{OH}^{-}$ions amplified by a multiple-water entanglement network (MWEN) are necessary for neural excitability, and attenuating amplification is the mechanism of action of IAs.

\section{LORR ED 50 measurement}

To gain insight into how $\mathrm{H}_{3} \mathrm{O}^{+}$and $\mathrm{OH}^{-}$ions may affect anesthetic potency we examined the effects of additional loads of $\mathrm{H}_{3} \mathrm{O}^{+}$and $\mathrm{OH}^{-}$ions by injecting weak acids or bases into mouse lateral ventricle on LORR ED 50 for C57BL/6 male mice (aged 8 weeks) to a typical potent IA, sevoflurane. For comparison of the effects of equal amounts of overloaded $\mathrm{H}_{3} \mathrm{O}^{+}$or $\mathrm{OH}^{-}$ions on the anesthetic potency of sevoflurane, the $\mathrm{pH}$ values of the weak acids ammonium chloride and heparin sodium (11), were both 6.25 , and those of the weak bases sodium acetate and xanthohumol (11), were both 7.75 , with injection volumes of $2 \mu 1$. Our method was effective to determine drug-induced anesthetic effects (fig. S1), for the mice undergoing intracerebroventricular cannulation were regarded as intact animals (10). We found that injections of two controls, $0.9 \% \mathrm{NaCl}$ and ammonium acetate, did not affect the LORR ED E0 $_{5}$ (Fig. 1, A and B). Ammonium chloride (Fig. 1C) and heparin sodium (Fig. 1D) decreased the $\mathrm{ED}_{50}$. However, sodium acetate (Fig. 1E) and xanthohumol (Fig. 1F) increased the $\mathrm{ED}_{50}$. Because an increased $\mathrm{ED}_{50}$ means decreased potency of an IA and vice versa (12), these findings indicate that, regardless of the chemical structure, weak acids enhance whereas weak bases weaken the anesthetic potency of sevoflurane by changing the cerebral $\mathrm{pH}$ in opposite directions.

However, the net changes in $\mathrm{pH}$ in the mouse brain (13) resulting from the intracerebroventricular injections of weak acids and bases were as small as $0.001 \mathrm{pH}$ units or even less, which were equivalent to a net increase or decrease of 137 free $\mathrm{H}_{3} \mathrm{O}^{+}$or $\mathrm{OH}^{-}$ions in a pyramidal cell, for example (supplementary text). How could the ultralow changes in cerebral $\mathrm{H}_{3} \mathrm{O}^{+}$or $\mathrm{OH}^{-}$ions affect anesthetic potency so considerably? Apparently, there should exist a system which can amplify the ultralow changes in cerebral $\mathrm{H}_{3} \mathrm{O}^{+}$or $\mathrm{OH}^{-}$ions for a considerable manifestation of anesthetic effects. Quantum mechanics has an innate characteristic of amplification $(14,15)$. In living system, quantum amplification has been found to function in avian compasses (16).

\section{MWEN-mediated amplification}

The existence of MWEN has been repeatedly implied (17-20) and been observed in liquid water (21). We postulated that an MWEN may be the system able to amplify 


\section{$\mathrm{H}_{3} \mathrm{O}^{+}$and $\mathrm{OH}^{-}$ions.}

To verify the postulation, we first formulated a scheme for an MWEN using onedimensional Ising model, based on the fact that both $\mathrm{H}_{3} \mathrm{O}^{+}$and $\mathrm{OH}^{-}$ions have total nuclear spins of $\frac{1}{2}$. In liquid water, electric field fluctuations result in $\mathrm{H}_{2} \mathrm{O}$ molecules dissociating and subsequently drive nascent $\mathrm{H}_{3} \mathrm{O}^{+}$and $\mathrm{OH}^{-}$ions to move rapidly away from each other to a distance too far for them to reinstate into their initial $\mathrm{H}_{2} \mathrm{O}$ molecule because the electrostatic attraction between them fades (22). Therefore, it is most likely for the pair of ions to combine with nearby counterions dissociated from other $\mathrm{H}_{2} \mathrm{O}$ molecules. Because the two hydrogen atoms in a $\mathrm{H}_{2} \mathrm{O}$ molecule (ortho- or para- $\left.\mathrm{H}_{2} \mathrm{O}\right)$ are indistinguishable and nuclear-spin entangled, the nascent $\mathrm{H}_{3} \mathrm{O}^{+}$and $\mathrm{OH}^{-}$ions inherit the indistinguishability and entanglement from their initial $\mathrm{H}_{2} \mathrm{O}$ molecule, analogous to the nuclear-spin entanglement between the two separated phosphorus ions cleaved from a diphosphate molecule (8).

According to the method described by Teng and Sy (23), we derived a 1-d Ising model to describe that the spins of $\mathrm{H}_{3} \mathrm{O}^{+}$and $\mathrm{OH}^{-}$ions are naturally entangled.

Because the total nuclear spins of $\mathrm{H}_{3} \mathrm{O}^{+}$and $\mathrm{OH}^{-}$ions are of $\frac{1}{2}$, the Hamiltonian of the Ising chain is

$$
H=-2 J \sum_{i, a} S_{i} S_{i+a}-g \mu B \sum_{i} S_{i}
$$

where $J, g$ and $\mu$ have the traditional meanings, $S_{i}$ is the spin for the $i$ th ion in the spin lattice, $i$ and $i+a$ are indices labelling the adjacent ions, and $B$ is the magnitude of the external magnetic field that can align the spins along its direction irrespective of the temperature (24).

According to Green's function, the function of the site-spin (with $B \neq 0$ ) for the Ising chain (24) is

$$
\begin{aligned}
& \left\langle S_{i}\right\rangle=a_{0}+2 a_{1}\left\langle S_{i}\right\rangle+a_{2}\left\langle S_{i-a} S_{i+a}\right\rangle, \\
& \text { where }\left\{\begin{array}{l}
a_{0}=\frac{1}{8}[\tanh (2 K+L)+2 \tanh L-\tanh (2 K-L)] \\
a_{1}=\frac{1}{4}[\tanh (2 K+L)+\tanh (2 K-L)] \\
a_{2}=\frac{1}{2}[\tanh (2 K+L)-2 \tanh L-\tanh (2 K-L)]
\end{array}\right.
\end{aligned}
$$

and $L=g \mu B / 2 k_{B} T$ and $K=J / 2 k_{B} T$.

In the absence of external magnetic field, for the two-site spin correlations we have

$$
\left\{\begin{array}{l}
\left\langle S_{i} S_{i+a}\right\rangle=\frac{1}{4} \tanh (K) \equiv \frac{1}{4} N 1(K, 1) \\
\left\langle S_{i} S_{i+2 a}\right\rangle=\frac{1}{4} \tanh ^{2}(K) \equiv \frac{1}{4} N 1(K, 2) \\
\left\langle S_{i} S_{i+n a}\right\rangle=\frac{1}{4} \tanh ^{\mathrm{n}}(K) \equiv \frac{1}{4} N 1(K, n) .
\end{array}\right.
$$

Evidently, there always exists

$$
\left\langle S_{i} \equiv 0\right\rangle \text {. }
$$

Apparently, equation 4 requires that, in order to keep the average values of the two-site spins to be $\frac{1}{4}$, the spin configuration must be in alignment. Equation 5 requires that, in order to maintain the average value of the single-site spin to be zero, the number of up-spins must equal that of down-spins. Particles are entangled in the Ising chain if and only if they fulfil the two requirements. Do $\mathrm{H}_{3} \mathrm{O}^{+}$and $\mathrm{OH}^{-}$ions 
fulfill the requirements? The nuclear spin configuration of hydrogen nuclei within ortho- or para-water molecules is in alignment, which is inherited by $\mathrm{H}_{3} \mathrm{O}^{+}$and $\mathrm{OH}^{-}$ ions when water dissociation takes place. Therefore, the spin configuration of $\mathrm{H}_{3} \mathrm{O}^{+}$ and $\mathrm{OH}^{-}$ions fulfils the first requirement. Water dissociations yield equal numbers of $\mathrm{H}_{3} \mathrm{O}^{+}$and $\mathrm{OH}^{-}$ions. In average, the numbers of up-spins and down-spins are equal. $\mathrm{H}_{3} \mathrm{O}^{+}$and $\mathrm{OH}^{-}$ions thus fulfill the second requirement as well. Therefore, the nuclear spins of $\mathrm{H}_{3} \mathrm{O}^{+}$and $\mathrm{OH}^{-}$ions must be entangled in the Ising chain at any finite temperature irrespective of external magnetic field (23). The entangled network of $\mathrm{H}_{3} \mathrm{O}^{+}$and $\mathrm{OH}^{-}$ions is termed as an MWEN for simplification of description.

We next calculated the amplification capacity of an MWEN. In neutral liquid water, $\mathrm{H}_{3} \mathrm{O}^{+}$and $\mathrm{OH}^{-}$ions are far away from each other, with a dissociation constant of water, $K_{\mathrm{w}}$, of $1 \times 10^{-14}$ at $25 \square$. The recombination of $\mathrm{H}_{3} \mathrm{O}^{+}$and $\mathrm{OH}^{-}$ions under this condition can be effectively described by the Eigen and de Maeyer (25) model. According to the model, the lifetime of $\mathrm{H}_{3} \mathrm{O}^{+}$or $\mathrm{OH}^{-}$ions is $10^{-4} \mathrm{~s}$. To maintain the equilibrium of $\mathrm{H}_{3} \mathrm{O}^{+}$and $\mathrm{OH}^{-}$ion concentrations in water, neutralization of a pair of $\mathrm{H}_{3} \mathrm{O}^{+}$and $\mathrm{OH}^{-}$ions produces a new pair at the same time. That is, two numbers are possibly added to the MWEN in every $10^{-4} \mathrm{~s}$ interval. We next consider the decoherence of an MWEN. An MWEN is composed of hydrogen nuclei with nuclear spins of $\frac{1}{2}$. The nuclei thus do not couple to electric fields; they interact with the environment only through magnetic fields, e.g., dipole fields from nuclear spins external to the MWEN. Therefore, the primary mechanism for decoherence of the network is entanglement of the hydrogen nuclei spins within the network with external nuclear spins. The decoherence time for the hydrogen spins in an MWEN is the nuclear magnetic resonance (NMR) spin-lattice relaxation time $T_{1}$, analogous to the decoherence time of spins of phosphorus nuclei within a Posner molecule (26). Given $N$ as the number in the MWEN, and $T_{1}$ as the decoherence time of any number in the network, the decoherence time, $t_{\mathrm{de}}$, of the entire network is $t_{\mathrm{de}}=T_{1} / N$. Given $t_{\mathrm{H}}$ the mean lifetime of $\mathrm{H}_{3} \mathrm{O}^{+}$or $\mathrm{OH}^{-}$ions and $t_{\text {ent }}$, the time needed for the formation of the entire network, and because two numbers are added to the network every $t_{\mathrm{H}}$, we have $t_{\mathrm{ent}}=\frac{N t_{\mathrm{H}}}{2}$. Because $t_{\mathrm{ent}}=t_{\mathrm{de}}$, we have $N=\sqrt{\frac{2 T_{1}}{t_{\mathrm{H}}}}$ and $t_{\mathrm{de}}=\sqrt{\frac{T_{1} t_{\mathrm{H}}}{2}}$. Inserting $T_{1}=3$ $\mathrm{s}(27)$ and $t_{\mathrm{H}}=10^{-4} \mathrm{~s}(25)$ into the equations, we obtain roughly $N=250$ and $t_{\mathrm{de}}=10^{-2} \mathrm{~s}$. The formation-disruption frequency of the MWEN, $f$, is $f=N / T_{1} \sim 100 \mathrm{~Hz}$.

These calculations indicate that, under ideal conditions, 250 numbers will be added to the network in every $10^{-2} \mathrm{~s}$ interval. When a collapse happens, the entire network will be suddenly broken. The breaking results in all entangled particles within the network simultaneously becoming real ions (Fig. 2). That is, at least one hundred $\mathrm{OH}^{-}$ions and equal $\mathrm{H}_{3} \mathrm{O}^{+}$ions suddenly appear.

Note that the above calculations considered only a one-by-one pattern of waterdissociation events contributing to the network. Most likely, many water-dissociation events may co-contribute to the network at the same time. An MWEN with cocontributions from many events will be far larger than that from a one-by-one contribution.

Notably, only the water molecules within the hypercoordinations of $\mathrm{OH}^{-}$ions are likely to dissociate (28). Therefore, the preexisting $\mathrm{OH}^{-}$ions are the only contributors to the number of an MWEN. Since the disruption of an MWEN will produce at least a hundred-fold more $\mathrm{OH}^{-}$ions than preexisting $\mathrm{OH}^{-}$ions, an MWEN has a great ability to amplify preexisting $\mathrm{OH}^{-}$ions. Increased preexisting $\mathrm{OH}^{-}$ions will promote the 
formation of a larger MWEN through increased co-contributions. Disruption of a larger MWEN will yield more $\mathrm{OH}^{-}$ions. On the other hand, increased $\mathrm{H}_{3} \mathrm{O}^{+}$ions will attenuate the amplification by annihilating the preexisting $\mathrm{OH}^{-}$ions.

\section{MWEN-amplified $\mathrm{OH}^{-}$ions and neuronal excitability}

We next linked MWEN-amplified $\mathrm{OH}^{-}$ions to increased neural excitability. For increased neural excitability means more anesthetic requirements to anesthetize humans or animals and vice versa (3), MWEN amplification capacity may account for the above LORR $\mathrm{ED}_{50}$ results.

Of the parameters of an MWEN, the formation-disruption frequency, $f$, is important because $f$ may tune the frequencies of conformational fluctuations of proteins and therefore neural excitability. Proteins feature spontaneously intrinsic fluctuations-transitions from one conformational state to another and back, which correspondingly alter their sensitivities to effectors (29). $\mathrm{OH}^{-}$ions are hydrophobic (30-32), which ensures that $\mathrm{OH}^{-}$ions penetrate the hydrophobic pockets within proteins. Penetration of a swarm of $\mathrm{OH}^{-}$ions, resulting from the disruption of an MWEN, may disrupt the van der Waals forces that normally shape proteins, not only by the mere occupancy but also by the electrostatic forces that the ions carry. An MWEN may thus tune the frequencies of protein conformational fluctuations and therefore their activities or functions. In neurons, the tunning may make ion channels operate cooperatively (33). The cooperativity may account for the opposing $\mathrm{pH}$ correlated activities of $N$-methyl-D-aspartate (34) (excitatory) and $\gamma$-aminobutyric acid (35) (inhibitory) receptors, and therefore differing neuronal excitabilities. Higher frequency means that the neuron possesses increased capacity to process information input in the form of action potential frequencies. When a neuron has a low frequency, it will miss some information because some action potentials will be input during the refractory periods of the neuron, that is, the neuron has decreased excitability. Neuronal spiking rates are indicators of neuronal excitability. We next recorded the spiking rates of cultured mouse primary cortical neurons (fig. S2) exposed to the in vivo dosages of weak acids and bases used to determine LORR $\mathrm{ED}_{50}$ above. We found, as predicted, that weak acids (Fig. 3, A and B) decreased whereas weak bases (Fig. 3, $\mathrm{C}$ and $\mathrm{D}$ ) increased spiking rates, indicating that acids lead to a decrease whereas bases an increase in neuronal excitability.

\section{IAs targeting at formation of an MWEN}

Because $f$ accounts for neuronal excitability, we next explored whether IAs produce general anesthesia by reducing $f$. Because $f=N / T_{1}$, to reduce $f$, IAs may ether reduce $N$, prolong $T_{1}$ or both. Because IAs such as xenon (36) and isoflurane (37) at clinically relevant concentrations have negligible effects on $T_{1}$, reducing $N$ may be the determinant for IAs to reduce $f$.

We used molecular dynamics simulations to calculate the binding energy released when one IA molecule binds with one water molecule $(38,39)$. The binding energy, usually negative (exothermic), represents the water dissociation capacity, which determines $N$. A more negative value means that more energy is needed for the combined water molecule to dissociate and, therefore, that $N$ is smaller. Inert (argon, krypton, and xenon) and conventional (isoflurane, desflurane, sevoflurane, and nitrous oxide) anesthetics and a trial anesthetic, F3 (1-chloro-1,2,2-trifluorocyclobutane), were selected (supplementary text), and their binding energies were calculated. We found that the anesthetic potencies of the selected anesthetics correlated remarkably well with their absolute binding energies (Fig. 4, A and B, and figs. S3 and S4 and Table S1), indicating that a reduction in the water dissociation capacity and a 
consequent weakening of the MWEN formation is responsible for the anesthetic effect of IAs.

We next used our model to explain some anesthetic phenomena that have not yet been clearly explained. The first is the isotopic dependence of xenon anesthesia (3). Because our calculations showed that xenon isotopes have identical binding energies (fig. S3), different effects of xenon isotopes on $T_{1}$ may account for the isotopic dependence of xenon anesthesia. Shortening $T_{1}$ is possible because ${ }^{129}$ xenon and ${ }^{131}$ xenon have nonzero nuclear spins, which may cross-relax with hydrogen nuclear spins (40). We measured the values of $T_{1}^{\mathrm{H}}$ in ${ }^{129}$ xenon-, ${ }^{131}$ xenon- and ${ }^{134}$ xenon-water solutions by using nuclear magnetic resonance imaging and accordingly calculated the $f$ ratios. We found that the $f$ ratios of ${ }^{129}$ xenon and ${ }^{131}$ xenon to ${ }^{134}$ xenon were quantitively in accord with their LORR $\mathrm{ED}_{50}$ values (Table 1 and fig. S5), suggesting that cross-relaxation is the reason for the lower potency of ${ }^{129}$ xenon and ${ }^{131}$ xenon.

Non-immobilizers, such as F6 (1,2-dichlorohexafluorocyclobutane) and F8 (2,3sdichlorooctafluorobutane), are inhaled compounds that are predicted to be anesthetics from their lipid solubility but do not cause immobility (12). Plotting the binding energies of F6 and F8 in Fig. 4B showed that the minimum alveolar concentrations (MACs) of F6 and F8 in rats are 31,436 atm and 4,210 atm, respectively, which are too high to be anesthetics. Helium and neon are nonanesthetics because their MACs are as high as 81,143 atm and 6,382 atm (Fig. 4A), respectively.

Whether IAs have stereoselectivity is under debate. $S$-(+)-Isoflurane was found to be more potent than $R$-(-)-isoflurane when intravenously injected (41), but no difference was found when inhaled (42) by rats. We found that $S$-(+)-isoflurane and $R$ (-)-isoflurane have identical binding energies (Table S1), suggesting that isoflurane has no anesthetic stereoselectivity, consistent with the fact that IAs act at nonspecific sites.

\section{Discussion}

The present knowledge suggests that anesthesia results from IAs occupying hydrophobic pockets within target proteins $(7,9)$. The mere presence of IAs in hydrophobic pockets, however, presents insurmountable problems. Protein pockets are usually highly selective for ligand shape and size (2). Fitting IAs with highly diverse shapes and sizes into structurally selective pockets is problematic. In fact, few proteins possess pockets large enough to accommodate large anesthetics such as halothane (43). Furthermore, some compounds occupy the same pockets but do not exert anesthetic effects or even have contrasting effects (1). Apparently, components that bridge IAs and protein pockets should be needed. This study indicates that MWEN-amplified $\mathrm{OH}^{-}$ions are these components because our model can easily explain the isotopic dependence of xenon anesthesia, non-immobilizers, and anesthetic stereoselectivity aforementioned. In addition, our model can explain the pressure reversal and why anesthesia populates living organisms. The reversal of anesthesia by high pressure, termed pressure reversal, has been repeatedly observed in different animal species (44-46). High pressure enhances water dissociation (47, 48), acting as an increase in the preexisting $\mathrm{OH}^{-}$ions in this study. According to our model, if the pressure is high enough, the water dissociation capacity may increase to a level that can fully compensate for the capacity loss caused by the IA, and eventually, the anesthesia is completely reversed. Our model is established on the basis of a causally complete rule-energy minima. Undoubtedly, this causation is applicable to all IAs and 
to all living organisms-IAs can anaesthetize all living organisms tested thus far, from Paramecium to humans to plant (6). Taken together, our model offers a unified mechanism for the anesthetic action of IAs.

Due to the many similarities between general anesthesia and sleep $(1,6)$ (the flip side of consciousness), this study suggests that general anesthesia, sleep and consciousness may share a single and simple common mechanism-the MWEN-based amplification of $\mathrm{OH}^{-}$ions. Evidence has indicated that the persistent excitability of neurons results in gradual neuronal acidification (49) and that sleep deprivation causes brain acidification (50). It is thus reasonable to believe that sleep restores neuronal alkalization that has been consumed by consciousness processing. 


\section{References}

1. S. R. Hameroff, The entwined mysteries of anesthesia and consciousness. Anesthesiology 105, 400-412 (2006).

2. L. Turin, E. M. C. Skoulakis, A. P. Horsfield, Electron spin changes during general anesthesia in Drosophila. Proc. Natl. Acad. Sci. U. S. A. 111, E3524E3533 (2014).

3. N. Li, D. Lu, L. Yang, H. Tao, Y. Xu, C. Wang, L. Fu, H. Liu, Y. Chummum, S. Zhang, Nuclear spin attenuates the anesthetic potency of xenon isotopes in mice: Implications for the mechanisms of anesthesia and consciousness. Anesthesiology 129, 271-277 (2018).

4. T. J. A. Craddock, S. R. Hameroff, A. T. Ayoub, M. Klobukowski, J. A. Tuszynski, Anesthetics act in quantum channels in brain microtubules to prevent consciousness. Curr. Top. Med. Chem. 15, 523-533 (2015).

5. H. T. Ton, T. X. Phan, A. M. Abramyan, L. Shi, G. P. Ahern, Identification of a putative binding site critical for general anesthetic activation of TRPA1. Proc. Natl. Acad. Sci. U. S. A. 114, 3762-3767 (2017).

6. M. B. Kelz, G. A. Mashour, The biology of general anesthesia from Paramecium to Primate. Curr. Biol. 29, R1199-R1210 (2019).

7. S.R. Hameroff, Anesthesia, consciousness and hydrophobic pockets-a unitary quantum hypothesis of anesthetic action. Toxicol. Lett. 100-101, 31-39 (1998).

8. M. P. A. Fisher, Quantum cognition: The possibility of processing with nuclear spins in the brain. Ann. Phys. 362, 593-602 (2015).

9. J. M. Sonner, R. S. Cantor, Molecular mechanisms of drug action: an emerging view. Annu. Rev. Biophys. 42, 143-167 (2013).

10. R. Chen, N. Li, H. Qian, R. Zhao, S. Zhang, Experimental evidence refuting the assumption of phosphorus-31 nuclear-spin entanglement-mediated consciousness. J. Integr. Neurosci. 19, 595-600 (2020).

11. N. Kathagen, P. Prehm, Regulation of intracellular $\mathrm{pH}$ by glycosaminoglycans. $J$. Cell. Physiol. 228, 2071-2075 (2013).

12. D. D. Koblin, B. S. Chortkoff, M. J. Laster, E. I. Eger $\square$, M. J. Halsey, P. Ionescu, Polyhalogenated and perfluorinated compounds that disobey the Meyer- Overton hypothesis. Anesth. Analg. 79, 1043-1048 (1994).

13. R. A. Rudick, D. K. Zirretta, R. M. Herndon, Clearance of albumin from mouse subarachnoid space: a measure of CSF bulk flow. J. Neurosci. Methods 6, 253259 (1982).

14. F. De Martini, Amplification of quantum entanglement. Phys. Rev. Lett. 81, 2842 2845 (1998).

15. S. Pang, J. Dressel, T. A. Brun, Entanglement-assisted weak value amplification. Phys. Rev. Lett. 113, 030401 (2014).

16. D. R. Kattnig, E. W. Evans, V. Déjean, C. A. Dodson, M. I. Wallace, S. R. Mackenzie, C. R. Timmel, P. J. Hore, Chemical amplification of magnetic field effects relevant to avian magnetoreception. Nat. Chem. 8, 384-391 (2016).

17. C. A. Chatzidimitriou-Dreismann, T. A Redah, R. M. F. Streffer, J. Mayers, Anomalous deep inelastic neutron scattering from liquid $\mathrm{H}_{2} \mathrm{O}-\mathrm{D}_{2} \mathrm{O}$ : Evidence of nuclear quantum entanglement. Phys. Rev. Lett. 79, 2839-2842 (1997).

18. C. A. Chatzidimitriou-Dreismann, J. Mayers, Anomalous neutron and Raman scattering due to EPR correlated protons in liquid water. Phys. B Condensed Matter 226, 231-233 (1996). 
19. A. K. Soper, C. J. Benmore, Quantum differences between heavy and light water. Phys. Rev. Lett. 101, 065502 (2008).

20. H. Weingärtner, C. A. Chatzidimttriou-Dreismann, Anomalous $\mathrm{H}^{+}$and $\mathrm{D}^{+}$ conductance in $\mathrm{H}_{2} \mathrm{O}-\mathrm{D}_{2} \mathrm{O}$ mixtures. Nature 346, 548-550 (1990).

21. H. Hu, M. Wu, Evidence of non-local physical, chemical and biological effects supports quantum brain. NeuroQuantology 4, 291-306 (2006).

22. P. L. Geissler, C. Dellago, D. Chandler, J. Hutter, M. Parrinello, Autoionization in liquid water. Science 291, 2121-2124 (2001).

23. B. Teng, H. K. Sy, Spin correlations in the Ising chains. Solid State Commun. 130, 193-197 (2004).

24. B. Teng, Y. Chen, H. Fu, Y. Tang, M. Tu, Y. Chen, J. Tang, Comparison between the nearest and the next-nearest neighbor site-spin interactions in the Ising model. Solid State Commun. 124, 347-351 (2002).

25. M. Eigen, L. de Maeyer, Self-dissociation and protonic charge transport in water and ice. Proc. R. Soc. London. Ser. A. Math. Phys. Sci. 247, 505-533 (1958).

26. M. W. Swift, C. G. Van de Walle, M. P. A. Fisher, Posner molecules: from atomic structure to nuclear spins. Phys. Chem. Chem. Phys. 20, 12373-12380 (2018).

27. D. C. Chang, C. F. Hazlewood, B. L. Nichols, H. E. Rorschach, Spin echo studies on cellular water. Nature 235, 170-171 (1972).

28. A. Hassanali, M. K. Prakash, H. Eshet, M. Parrinello, On the recombination of hydronium and hydroxide ions in water. Proc. Natl. Acad. Sci. U. S. A. 108, 20410-20415 (2011).

29. H. N. Motlagh, J. O. Wrabl, J. Li, V. J. Hilser, The ensemble nature of allostery. Nature 508, 331-339 (2014).

30. R. Zangi, J. B. F. N. Engberts, Physisorption of hydroxide ions from aqueous solution to a hydrophobic surface. J. Am. Chem. Soc. 127, 2272-2276 (2005).

31. K. N. Kudin, R. Car, Why are water-hydrophobic interfaces charged? J. Am. Chem. Soc. 130, 3915-3919 (2008).

32. T. H. Vu, M. J. Shultz, Vibrating hydroxide in hydrophobic solution: The ion to keep an eye on. Chem. Phys. Lett. 572, 13-15 (2013).

33. Y. Liu, J. P. Dilger, Application of the one- and two-dimensional Ising models to studies of cooperativity between ion channels. Biophys. J. 64, 26-35 (1993).

34. S. F. Traynelis, S. G. Cull-Candy, Proton inhibition of N-methyl-D-aspartate receptors in cerebellar neurons. Nature 345, 347-350 (1990).

35. K. Kaila, P. Paalasmaa, T. Taira, J. Voipio, $\mathrm{pH}$ transients due to monosynaptic activation of $\mathrm{GABA}_{\mathrm{A}}$ receptors in rat hippocampal slices. Neuroreport 3, 105-108 (1992).

36. T. R. Stengle, N. V Reo, K. L. Williamson, Nuclear magnetic relaxation of xenon131 in solution. The influence of solvent electric moment and dynamics on solute relaxation. J. Phys. Chem. 88, 3225-3228 (1984).

37. P. Holzmüller, E. Moser, A. Werba, E. M. Markis, G. Gomiscek, In vitro NMR investigation of controlled single and repeated isoflurane anesthesia. Magn. Reson. Imaging 10, 393-400 (1992).

38. D. Sutradhar, T. Zeegers-Huyskens, A. K. Chandra, A theoretical investigation on the conformation and the interaction of $\mathrm{CHF}_{2} \mathrm{OCF}_{2} \mathrm{CHF}_{2}$ (desflurane II) with one water molecule. J. Mol. Model. 19, 5045-5052 (2013).

39. D. Sutradhar, T. Zeegers-Huyskens, A. K. Chandra, Strong hyperconjugative interactions in isolated and water complexes of desflurane: a theoretical investigation. J. Phys. Chem. A. 117, 8545-8554 (2013). 
40. I. E. Dimitrov, R. Reddy, J. S. Leigh, Intermolecular dipole-dipole relaxation of ${ }^{129}$ Xe dissolved in water. J. Magn. Reson. 145, 302-306 (2000).

41. R. Dickinson, I. White, W. R. Lieb, N. P. Franks, Stereoselective loss of righting reflex in rats by isoflurane. Anesthesiology 93, 837-843 (2000).

42. E. I. Eger $\square$, D. D. Koblin, M. J. Laster, V. Schurig, M. Juza, P. Ionescu, D. Gong, Minimum alveolar anesthetic concentration values for the enantiomers of isoflurane differ minimally. Anesth. Analg. 85, 188-192 (1997).

43. M. F. Eckenhoff, K. Chan, R. G. Eckenhoff, Multiple specific binding targets for inhaled anesthetics in the mammalian brain. J. Pharmacol. Exp. Ther. 300, 172179 (2002).

44. D. W. Kent, M. J. Halsey, E. I. Eger $\square$, B. Kent, Isoflurane anesthesia and pressure antagonism in mice. Anesth. Analg. 56, 97-101 (1977).

45. E. B. Smith, F. Bowser-Riley, S. Daniels, I. T. Dunbar, C. B. Harrison, W. D. M. Paton, Species variation and the mechanism of pressure-anaesthetic interactions. Nature 311, 56-57 (1984).

46. S. M. Johnson, K. W. Miller, Antagonism of pressure and anaesthesia. Nature 228, 75-76 (1970).

47. E. Schwegler, G. Galli, F. Gygi, R. Q. Hood, Dissociation of water under pressure. Phys. Rev. Lett. 87, 265501 (2001).

48. B. Liu, Y. Gao, Y. Han, Y. Ma, C. Gao, In situ electrical conductivity measurements of $\mathrm{H}_{2} \mathrm{O}$ under static pressure up to $28 \mathrm{GPa}$. Phys. Lett. A. 380, 2979-2983 (2016).

49. U. Bonnet, D. Bingmann, E.J. Speckmann, M. Wiemann, Small intraneuronal acidification via short-chain monocarboxylates: First evidence of an inhibitory action on over-excited human neocortical neurons. Life Sci. 204, 65-70 (2018).

50. D. T. Plante, G. H. Trksak, J. E. Jensen, D. M. Penetar, C. Ravichandran, B. A. Riedner, W. L. Tartarini, C. M. Dorsey, P. F. Renshaw, S. E. Lukas, D. G. Harper, Gray matter-specific changes in brain bioenergetics after acute sleep deprivation: $\mathrm{a}{ }^{31} \mathrm{P}$ magnetic resonance spectroscopy study at 4 Tesla. Sleep $37,1919-1927$ (2014).

51. S. Kaech, G. Banker, Culturing hippocampal neurons. Nat. Protoc. 1, 2406-2415 (2006).

52. C. Zhou, C. Qi, J. Zhao, F. Wang, W. Zhang, C. Li, J. Jing, X. Kang, Z. Chai, Interleukin- $1 \beta$ inhibits voltage-gated sodium currents in a time- and dosedependent manner in cortical neurons. Neurochem. Res. 36, 1116-1123 (2011).

53. D. Gaszowski, M. Ilczyszyn, Hydrogen bonding to xenon: A comparison with neon, argon and krypton complexes. Chem. Phys. Lett. 556, 59-64 (2013).

54. F. Neese, Software update: the ORCA program system, version 4.0. Wiley Interdiscip. Rev. Comput. Mol. Sci. 8, 1-6 (2017).

55. F. Weigend, R. Ahlrichs, Balanced basis sets of split valence, triple zeta valence and quadruple zeta valence quality for $\mathrm{H}$ to $\mathrm{Rn}$ : Design and assessment of accuracy. Phys. Chem. Chem. Phys. 7, 3297-3305 (2005).

56. M. D. Hanwell, D. E. Curtis, D. C. Lonie, T. Vandermeersch, E. Zurek, G. R. Hutchison, Avogadro: an advanced semantic chemical editor, visualization, and analysis platform. J. Cheminform. 4, 17 (2012).

57. M. Hosseini-Sharifabad, J. R. Nyengaard, Design-based estimation of neuronal number and individual neuronal volume in the rat hippocampus. J. Neurosci. Methods 162, 206-214 (2007). 
58. F. Sartori, A. S. Hafner, A. Karimi, A. Nold, Y. Fonkeu, E. M. Schuman, T. Tchumatchenko, Statistical laws of protein motion in neuronal dendritic trees. Cell Rep. 33, 108391 (2020).

59. J. M. Sonner, J. F. Antognini, R. C. Dutton, P. Flood, A. T. Gray, R. A. Harris, G. E. Homanics, J. Kendig, B. Orser, D. E. Raines, J. Trudell, B. Vissel, E. I. Eger $\square$, Inhaled anesthetics and immobility: Mechanisms, mysteries, and minimum alveolar anesthetic concentration. Anesth. Analg. 97, 718-740 (2003).

60. D. D. Koblin, Z. Fang, E. I. Eger $\square$, M. J. Laster, D. Gong, P. Ionescu, M. J. Halsey, J. R. Trudell, Minimum alveolar concentrations of noble gases, nitrogen, and sulfur hexafluoride in rats. Anesth. Analg. 87, 419-424 (1998).

61. C. T. Gonsowski, E. I. Eger $\square$, Nitrous oxide minimum alveolar anesthetic concentration in rats is greater than previously reported. Anesth. Analg. 79, 710712 (1994).

62. K. Solt, E. I. Eger $\square$, D. E. Raines, Differential modulation of human N-methyl-Daspartate receptors by structurally diverse general anesthetics. Anesth. Analg. 102, 1407-1411 (2006).

63. R.Sander, Compilation of Henry's law constants (version 4.0) for water as solvent. Atmos. Chem. Phys. 15, 4399-4981 (2015).

64. R. L. Davisson, G. Yang, T. G. Beltz, M. D. Cassell, A. K. Johnson, C. D. Sigmund, The brain renin-angiotensin system contributes to the hypertension in mice containing both the human renin and human angiotensinogen transgenes. Cir. Res. 83, 1047-1058 (1998).

65. C. Perrin, C. Knauf, R. Burcelin, Intracerebroventricular infusion of glucose, insulin, and the adenosine monophosphate-activated kinase activator, 5aminoimidazole-4-carboxamide-1- $\beta$-D-ribofuranoside, controls muscle glycogen synthesis. Endocrinology 145, 4025-4033 (2004).

Acknowledgements: We thank Heshui Wu, the MRI Room at Union Hospital, Wuhan, China, for help with MRI testing; Ping Yin, Department of Epidemiology and Biostatistics and State Key Laboratory of Environment Health, School of Public Health, Tongji Medical College, Huazhong University of Science and Technology, Wuhan, China, for statistical assistance; and Hong Ren, Department of Anesthesiology at Union Hospital, Wuhan, China, for assistance in electroneurophysiological experiments. Funding: This work was supported by the National Natural Science Foundation of China (grant 81670068 to S.Z.). Author contributions: H.Q. designed and performed the neuronal culture, MRI, and electroneurophysiological experiments, with assistance from R.C., D.L. and R.Z. N.L. and Q.H. designed the behavioral experiments that were conducted by D.L., R.Z. and R.C. L.Y. and Y.X. designed the molecular dynamic simulations, which were performed by L.Y., Y.X., H.L., N.C. and Q.Z. S.Z. conceptualized and supervised the study, analyzed the data, and wrote the manuscript with input from all authors. Competing interests: The authors declare no competing interests. Data and materials Availability: All data are available in the main text or the supplementary materials. All materials are available upon request from S.Z.

\section{Supplementary Materials:}

Materials and Methods

Supplementary text

Figs. S1 to S5 
bioRxiv preprint doi: https://doi.org/10.1101/2021.01.28.428716; this version posted January 30, 2021. The copyright holder for this preprint (which was not certified by peer review) is the author/funder. All rights reserved. No reuse allowed without permission.

Table S1

References (51-65) 


\section{Supplementary Materials for}

\section{Hydroxide ions amplified by water entanglement underly the mechanism of general anesthesia}

Hao Qian†, Na Li†, Lei Yang†, Younian Xu†, Rong Chen, Dongshi Lu, Ruihan Zhao, Hui Liu, Nanxue Cui, Qiao Zhou, Shihai,Zhang*

*Correspondence to S.Z.: zhv@ hust.edu.cn

$\dagger$ These authors contributed equally to this work.

This PDF file includes:

Materials and Methods

Supplementary Text

Figs. S1 to S5

Table S1

References (51-65) 


\section{Materials and Methods}

\section{Animals}

C57BL/6 male mice (7 weeks; weight range, 22-25 $\mathrm{g}$ ) and C57BL/6 female mice (postnatal days, 18-19) were ordered from Beijing Vital River Laboratory Animal Technology Co., Ltd. ([jing]2016-0006; China). The animals were bred in a temperature- and humidity-controlled room with a 12-h light/dark cycle. The animals had free access to standard mouse chow and tap water before the experiments. The animals used for behavioral experiments were housed in the room for a week. All animal operations and experimental protocols conformed to the US National Institutes of Health Guide for the Care and Use of Laboratory Animals (NIH Publications No. 8023, revised 1978) and were approved by the Institutional Animal Care and Use Committee (approval No: S164) at Tongji Medical College, Huazhong University of Science and Technology.

\section{Agents}

Sevoflurane was purchased from Maruishi Pharmaceutical Co., Ltd. (Chouku, Osaka, Japan). Heparin sodium was purchased from Changzhou Qianhong Biochemical Pharmaceutical Co., Ltd. (Changzhou, China). Xanthohumol was obtained from J\&K Scientific Ltd. (Beijing, China). ${ }^{129}$ Xenon, ${ }^{131}$ xenon and ${ }^{134}$ xenon gases were purchased from NUKEM Isotopes Imaging GmbH (Alzenau, Germany) and all had a purity $\geq 99.99 \%$ and an abundance of $93.5 \%$.

Culture media, including Dulbecco's modified Eagle's medium/F12 (1:1) (DMEM/F12), fetal bovine serum (FBS), $0.25 \%$ trypsin solution, calcium- and magnesium-free Hank's balanced salt solution (CMF-HBSS), phosphate-buffered saline (PBS), neurobasal medium and B-27 supplement, were purchased from Life Technologies Gibco® BRL (Grand Island, NY, USA). Poly-D-lysine, DNase I, penicillin/streptomycin, and L-glutamine were purchased from SigmaAldrich Co., Ltd. (St. Louis, MO, USA). All other reagents of analytical grade were purchased from Sinopharm Chemical Reagent Co., Ltd. (Shanghai, China).

\section{$\underline{\text { Solution preparations }}$}

All solutions were prepared immediately prior to the experiments. For the animal behavioral experiments, $1 \mathrm{mM}$ sodium acetate $\left(\mathrm{CH}_{3} \mathrm{COONa}\right), 1 \mathrm{mM}$ ammonium acetate $\left(\mathrm{CH}_{3} \mathrm{COONH}_{4}\right), 1$ $\mathrm{mM}$ ammonium chloride $\left(\mathrm{NH}_{4} \mathrm{Cl}\right)$, heparin sodium $62.5 \mathrm{U} / \mathrm{ml}$ and $74 \mu \mathrm{M}$ xanthohumol were prepared by dissolving in normal saline. All solutions were adjusted to an osmolality of $300 \pm 10$ mOsm with $\mathrm{NaCl}$ or tri-distilled water. The solutions were filtered through a $0.22-\mu \mathrm{m}$ filter (Millipore, Bedford, MA, USA) prior to use.

\section{$\underline{\text { LORR ED }} \underline{50}_{\underline{2}}$ determination}

To determine the LORR $\mathrm{ED}_{50}$, sixty $\mathrm{C} 57 \mathrm{BL} / 6$ male mice (8 weeks old) were divided randomly into saline, ammonium chloride, sodium acetate, ammonium acetate, heparin sodium, and xanthohumol groups, with 10 mice in each group. The LORR $\mathrm{ED}_{50}$ of sevoflurane in mice was determined according to our previously described method (10) with slight modifications. Briefly, the basal and drug-loaded LORR $\mathrm{ED}_{50}$ of each mouse was determined, and all the values were compared. For the basal LORR $\mathrm{ED}_{50}$ determination, mice were individually placed in an isolated plastic mesh V-shaped trough fixed in a clear plastic chamber $(205 \times 134 \times 69 \mathrm{~mm})$ with an electrical fan to mix gases. One side of the chamber was connected to a sevoflurane vaporizer (Aika, Ichikawa Shiseido, Tokyo, Japan). The other side was connected to an infrared gas monitor (BeneView T5, Mindray Bio-Medical Electronics, Shenzhen, China) to measure the sevoflurane, oxygen and carbon dioxide concentrations in real time. The monitor can measure the sevoflurane concentration with a precision of $0.01 \%$.

When a mouse was placed in the chamber, pure oxygen was immediately supplied at a rate of $600 \mathrm{ml} / \mathrm{min}$. When the chamber's oxygen concentration increased to $99 \%$, sevoflurane gas mixed in pure oxygen was provided by the vaporizer. The initial sevoflurane concentration in the chamber was $1.00 \%$, which was maintained for 15 minutes to equilibrate the mouse with sevoflurane gas. Then, the chamber was rotated $180^{\circ}$ to place the mouse on its back in the Vtrough, and its righting reflex was observed. LORR was defined as the supine mouse unable to turn itself onto all four paws three times within $1 \mathrm{~min}$. According to the mouse's righting reflex, a 
stepwise increase or decrease of $0.10 \%$ sevoflurane in the chamber was applied. Specifically, if the mouse's righting reflex disappeared, the sevoflurane concentration was decreased $0.10 \%$; otherwise, it was increased $0.10 \%$. After 15 minutes of equilibration at each sevoflurane concentration, the mouse's righting reflex was observed again. The LORR ED 50 was the average of the two critical sevoflurane concentrations at which the mouse either lost or regained its righting reflex (10). All righting reflexes were observed by a trained observer who was unaware of group allocation. All determinations were made between 08:00 and 18:00.

After basal LORR $\mathrm{ED}_{50}$ determination, the mouse underwent intracerebroventricular cannulation following our previously described method (10). After 1 day of recovery, the LORR $\mathrm{ED}_{50}$ of the mouse was determined again. Briefly, the mouse was sedated with $1 \%$ sevoflurane. Then, saline, ammonium acetate $(1 \mathrm{mM})$, sodium acetate $(1 \mathrm{mM})$, ammonium chloride $(1 \mathrm{mM})$, heparin sodium $(62.5 \mathrm{U} / \mathrm{ml})$, or xanthohumol $(74 \mu \mathrm{M})$ was injected into the lateral cerebral ventricle by a syringe pump system (RWD Life Science Co., Ltd., Shenzhen, China). All agents were warmed to $37{ }^{\circ} \mathrm{C}$ before infusion. The intracerebroventricular injection was performed automatically by the pump at a rate of $1 \mu \mathrm{l} / \mathrm{min}$. A total volume of $2 \mu \mathrm{l}$ was injected. After injection, sevoflurane was discontinued, and the mouse could recover. When the mouse could move freely, the LORR $\mathrm{ED}_{50}$ of sevoflurane in the animal was determined.

\section{Cortical neuron culture}

Primary culture of mouse cortical neurons was performed using a described method (51) with some modifications. In brief, under sevoflurane anesthesia, mouse embryos were removed from timed pregnant mice at embryonic day 18. The embryos were killed by decapitation quickly in ice-cold CMF-HBSS solution. Brains were rapidly dissected, and the cortex was cleared from the meninges and isolated under a dissection microscope. Cortices were collected in ice-cold CMF-HBSS with $0.2 \%$ D-glucose and $1 \%$ penicillin-streptomycin solution and were then homogenized. Next, the tissues were digested with $0.125 \%$ trypsin and $100 \mu \mathrm{g} / \mathrm{ml}$ DNase I in CMF-HBSS for $15 \mathrm{~min}$ at $37 \square$. After filtering the tissues through a sterile nylon sieve with a pore size of $70 \mu \mathrm{m}$, cells were collected by centrifugation for $5 \mathrm{~min}$ at $80 \mathrm{~g}$. The cells were suspended in DMEM/F12 containing $10 \% \mathrm{FBS}$ and $1 \%$ penicillin-streptomycin at $5 \times 10^{5}$ cells per ml and subsequently inoculated at $400 \mu \mathrm{l}$ per well into 24 -well culture plates containing coverslips (Flexcell International Co., Hillsborough, NC, USA). The coverslips were coated with poly-Dlysine $(100 \mu \mathrm{g} / \mathrm{ml})$. After $4 \mathrm{~h}$ of incubation in a humidified chamber provided with $5 \% \mathrm{CO}_{2}$ and $95 \%$ air at $37 \square$, the cells were washed three times with PBS and replaced with $400 \mu 1$ neurobasal/B27 medium supplemented with $500 \mu \mathrm{M}$ L-glutamine. Three days later, the culture medium was replaced with fresh culture medium lacking L-glutamine. Half of the medium was then replaced every 3 days. The cells were used for experiments after 11-14 days of culture.

\section{Electrophysiological recording}

Cultured primary cortical neurons were used to perform electrophysiological recording (52). Neuronal action potentials were obtained by using current-clamp mode. Cortical neurons cultured on coverslips were placed in the prefusion chamber with an extracellular solution with the following composition: $140 \mathrm{mM} \mathrm{NaCl}, 5 \mathrm{mM} \mathrm{KCl}, 1 \mathrm{mM} \mathrm{MgCl}_{2}, 2 \mathrm{mM} \mathrm{CaCl}$, and $10 \mathrm{mM}$ HEPES ( $\mathrm{pH}$ adjusted to 7.3-7.4 with $\mathrm{NaOH}$ ). The pipette solution consisted of $130 \mathrm{mM} \mathrm{KCl,} 10$ $\mathrm{mM} \mathrm{NaCl}, 1 \mathrm{mM} \mathrm{MgCl} 2,10 \mathrm{mM}$ EGTA, $10 \mathrm{mM}$ HEPES, $10 \mathrm{mM}$ glucose, and $2 \mathrm{mM}$ ATP-Na 2 ( $\mathrm{pH}$ adjusted to 7.2 -7.3 with $\mathrm{KOH}$ ). Patch pipettes were pulled to a tip resistance of 6-8 $\mathrm{M} \Omega$ using borosilicate glass capillary tubes with a P-1000 micropipette puller (Sutter Instrument, Novato, CA, USA). Current clamp recording was performed using a Multiclamp 700B amplifier (Axon Instruments, Foster City, CA, USA) equipped with a Digidata 1440 data acquisition system and pCLAMP 10 software (Axon Instruments, Foster City, CA). Data were digitized at $10 \mathrm{kHz}$. The cortical neurons were held at $0 \mathrm{pA}$. The action potentials were elicited using a depolarizing current of $100 \mathrm{pA}(500 \mathrm{~ms})$ to obtain the basal value. The cells were then exposed to dosages of the weak acids and bases (used to determine the LORR $\mathrm{ED}_{50}$ in the mice). The tested compounds were added to the extracellular solution and delivered through a perfusion system (Minipuls 3, Gilson International France SAS, Villiers-le-bel, France) at $37^{\circ} \mathrm{C}$ and a rate of $3 \mathrm{ml} / \mathrm{min}$ for $2 \mathrm{~min}$. Then, the neurons were perfused with extracellular solution $\left(37^{\circ} \mathrm{C}\right)$ without the tested compounds for 2 min to imitate drainage of the drug injected into cerebrospinal fluid. Drug-induced changes in the 
number of action potentials for the cells were elicited and recorded at $2 \mathrm{~min}$ of removal. All solutions were warmed and kept at $37^{\circ} \mathrm{C}$.

$T_{1}^{\mathrm{H}}$ acquisition

Oxygen was removed from the samples of xenon-water solutions by the following procedure. A 250-ml clear glass bottle was filled with $200 \mathrm{ml}$ tri-distilled water and then covered. A $21 \mathrm{G}$ needle was inserted into the cover of the bottle. The needle was kept open to let air out. The bottle was then warmed in a water bath at $60 \square$ overnight. Three bottles were prepared. After being warmed up, the bottles were first separately pressurized with ${ }^{129}$ xenon, ${ }^{131}$ xenon, and ${ }^{134}$ xenon gases for one minute, and then the gases were quickly flushed out. The pressurization-flushing procedure was repeated three times before the bottles were finally sealed. Water with an oxygen partial pressure as low as undetectable by an ABL800 FLEX blood gas analyzer (Radiometer Medical ApS, Brønshøj, Denmark) was sampled. The bottles were then separately filled with ${ }^{129}$ xenon, ${ }^{131}$ xenon, and ${ }^{134}$ xenon to 1 bar and sealed to let the xenon mix with the water overnight. Then, $30 \mathrm{ml}$ xenon-water solution was drawn into a 50-ml plastic syringe and sealed for the $T_{1}^{\mathrm{H}}$ test. Four samples were prepared for each isotope.

Magnetic resonance imaging (MRI) was performed to measure $T_{1}^{\mathrm{H}}$ values at the MRI Room of Department of Radiology at the Union Hospital of Tongji Medical College of Huazhong University of Science and Technology, Wuhan, China. We used a super-high-field superconducting 3.0 Tesla MRI scanner (Magnetom Trio, Siemens Healthcare Solutions, Inc., Erlangen, Germany) to obtain thin-section planar scans (1 mm section thickness) with a 32-channel head coil. All samples were measured at the same time. The imaging protocol consisted of axial T1-weighted imaging (T1WI) of fast spin echo sequences. T1WI as $T_{1}^{\mathrm{H}}$ was acquired with the following parameters: repetition time, $350 \mathrm{~ms}$; echo time, $11 \mathrm{~ms}$; field of view, $4.0 \times 4.0 \mathrm{~mm}$; matrix size, $256 \times 256$; and slice thickness, $1 \mathrm{~mm}$.

\section{$\underline{\text { Molecular dynamics simulations }}$}

For inert gases, the geometries of $\mathrm{XH}_{2} \mathrm{O}\left(\mathrm{X}=\right.$ helium, neon, argon, krypton, ${ }^{129}$ xenon, ${ }^{131}$ xenon, or ${ }^{134}$ xenon) complexes were optimized, and their binding energies were calculated using the QZVPP basis set at coupled-cluster singles and doubles with perturbative triple correction $[\mathrm{CCSD}(\mathrm{T})]$ at the def2-QZVPP level of theory (53) using the ORCA (54) suite of programs (version 4.2.0).

For conventional anesthetics, F3 and non-immobilizers, the geometries of $\mathrm{AH}_{2} \mathrm{O}(\mathrm{A}=$ nitrous oxide, isoflurane, sevoflurane, desflurane, F3, F6, or F8) complexes were fully optimized, and their binding energies and harmonic frequencies were calculated at density functional theory (DFT) (55) and the B3LYP/def2-TZVPPD level of theory, which were implemented in Gaussian 16W (version C.01 for Windows, Gaussian, Inc., Wallingford, CT, USA) suite of programs. For each complex, the harmonic vibrational frequencies and binding energies of all configurations were calculated. If configurations had imaginary frequencies, they were excluded from subsequent data analysis. For each complex, the configuration with the lowest binding energy was selected for subsequent data analysis according to the rule of energy minima. Avogadro (version 1.2.0) software (56) for Windows was used for molecular modelling and mapping.

\section{$\underline{\text { Statistics }}$}

Sample sizes were predetermined, and randomization and blinding were performed according to our previous study (10). Data are presented as the means \pm standard deviations. Single comparisons of within-group measures of the LORR $\mathrm{ED}_{50}$ and the number of action potentials were made by a two-tailed paired Student's $t$-test after the data were examined for normality of distributions using the Shapiro-Wilk test. The binding energy and $T_{1}^{\mathrm{H}}$ data were analyzed with linear regression. All analyses were performed using SAS version 9.4 (SAS Institute, Cary, NC, USA).

\section{Supplementary Text}

Drug-induced $\mathrm{pH}$ changes in the mouse brain

Take sodium acetate as an example. We found that the $\mathrm{pH}$ of $1 \mathrm{mM}$ sodium acetate at room 
temperature $(25 \square)$ was 7.75 , as measured with a pH meter. The $\mathrm{pH}$ of cerebrospinal fluid, $\mathrm{pH}_{\mathrm{c}}$, is 7.35 , and the total mouse brain volume (cerebrospinal fluid volume with cell component volume) is $462 \mu \mathrm{l}$ (13). The injection of $2 \mu \mathrm{l}$ of sodium acetate will replace $2 \mu \mathrm{l}$ of cerebrospinal fluid. The $\mathrm{H}^{+}$concentration of the mouse brain after injection of sodium acetate, $\left[\mathrm{H}^{+}\right]_{\mathrm{ac}}$, is $\left[\mathrm{H}^{+}\right]_{\mathrm{ac}}=\left[2 \times 10^{-7.75}\right.$ $\left.+460 \times 10^{-7.35}\right] / 462=10^{-7.351} \mathrm{M} . \mathrm{pH}_{\mathrm{ac}}=-\log \left[\mathrm{H}^{+}\right]_{\mathrm{ac}}=7.351 . \Delta \mathrm{pH}=\mathrm{pH}_{\mathrm{ac}}-\mathrm{pH}_{\mathrm{c}}=0.001$. That is, a 2 $\mu \mathrm{l}$ injection of $1 \mathrm{mM}$ sodium acetate into mouse cerebrospinal fluid caused a net change in the $\mathrm{pH}$ of the mouse brain of approximately 0.001 . The other three drugs would result in net $\mathrm{pH}$ changes similar to that from sodium acetate.

Because we are unable to know the average $\mathrm{pH}$ value in the brain of the intact mice, we take cerebrospinal fluid $\mathrm{pH}$ as brain $\mathrm{pH}$ into the above calculation. The intracellular $\mathrm{pH}$ is lower than that of cerebrospinal fluid. One can see that $\Delta \mathrm{pH}$ is also approximately 0.001 if $\mathrm{pH}$ value of 7.00 is taken into calculation. If the buffer systems of the brain and physiological drainage of cerebrospinal fluid are taken into consideration, the ${ }_{\Delta} \mathrm{pH}$ may be even less. A pyramidal cell, the largest cell of hippocampal neurons in the CA1 layer, is $1,660 \mu \mathrm{m}^{3}$ in cell volume (57). Inputting an intraneuronal $\mathrm{pH}$ of 7.00 and the fact that $60 \%$ of the cell volume is water into the calculation (58), we obtained 6,000 free $\mathrm{H}_{3} \mathrm{O}^{+}$ions in the cytoplasm of the cell. A decrease of $0.001 \mathrm{pH}$ units in the cytoplasm of the cell after intracerebroventricular injection of ammonium chloride, for example, is equivalent to a net increase of 137 free $\mathrm{H}_{3} \mathrm{O}^{+}$ions in a pyramidal cell.

\section{Inhaled anesthetics selected}

Inhaled anesthetics may have mediatory and modulatory effects. Mediatory effects are the mechanism-involved (direct) effects of inhaled anesthetics. Modulatory effects may modulate the aesthetic potency of inhaled anesthetics through non-mechanistic (indirect) routes (59) such as directly binding with lipids, receptors, or ion channels. For a given inhaled aesthetic, its potency, such as its MAC, is the sum of its mediatory and modulatory effects. The modulatory effects may thus strongly affect mechanistic studies because mechanistic studies rely on only mechanisminvolved MACs. This study is a mechanistic study. We thus had to select anesthetics with known minimal modulatory effects to plot Fig. 4 in the main text.

Different animal species may have different MACs. For a given animal species, different laboratories may obtain different MACs derived from different experimental paradigms involving different nociceptive stimuli. As such, in this study, the MACs of the inhaled anesthetics were cited from one laboratory (Department of Anesthesia and Perioperative Care, University of California, San Francisco, CA, USA) in one animal species, Sprague-Dawley rats. If discrepancies appeared, the most recently published data were cited. Finally, the MACs in Sprague-Dawley rats for inert gases (argon, krypton, and xenon) (60), nitrous oxide (61), conventional anesthetics (isoflurane, desflurane, and sevoflurane) (62), and F3 (1-chloro-1,2,2-trifluorocyclobutane) (12) were cited. The MACs were converted into aqueous $\mathrm{ED}_{50}$ values at $37 \square$ using Henry's law (63) to plot Fig. 4 in the main text. 
bioRxiv preprint doi: https://doi.org/10.1101/2021.01.28.428716; this version posted January 30, 2021. The copyright holder for this preprint (which was not certified by peer review) is the author/funder. All rights reserved. No reuse allowed without permission.

Fig. S1.

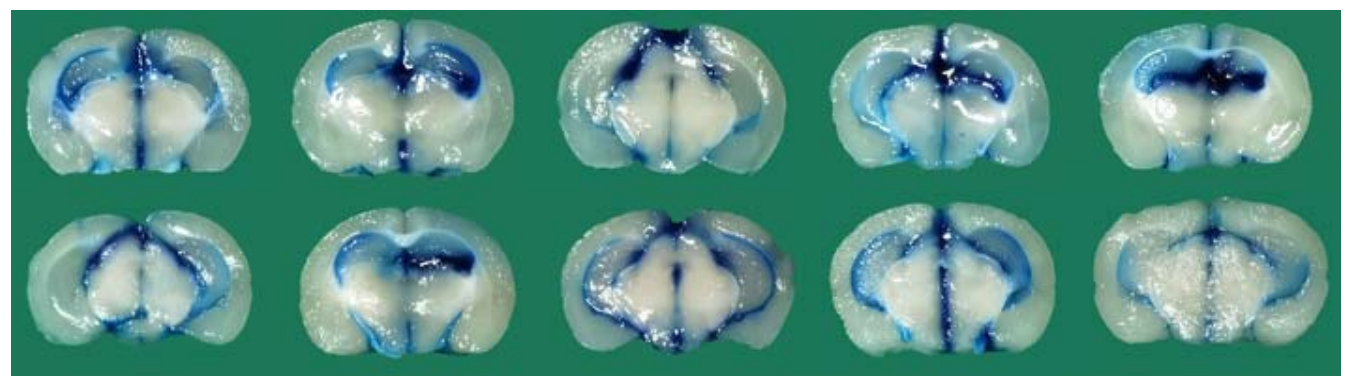

Fig. S1. Diffusion of Evans blue throughout mouse ventricular system. After righting reflex testing, 10 mice in the saline group were anesthetized with sevoflurane and then received injection of Evans blue $2 \mu \mathrm{l}$ into lateral ventricle through ventricular cannula, as the injection procedure as that of tested drugs. The mice were then decapitated, and the brain was removed to check the diffusion of Evans blue (64). The photos show that Evans blue diffuses well throughout all mouse ventricular systems, indicating that drug-induced anesthetic effects in Fig. 1 were resulted from global rather than local brain actions of the drugs. After righting reflex testing, all 50 mice in the other five groups were weighed and then housed for a week. The mice were then weighed again. For each mouse, its post-housing weight was compared with its pre-housing weight. If there was a weight loss, the mouse may suffer possible neural pathologic damage (65). We did not find any mouse with weight loss. 
Fig. S2.

DAPI
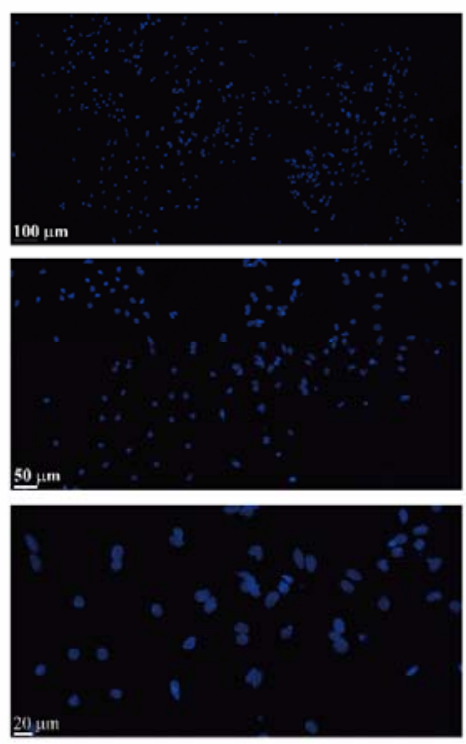

NeuN
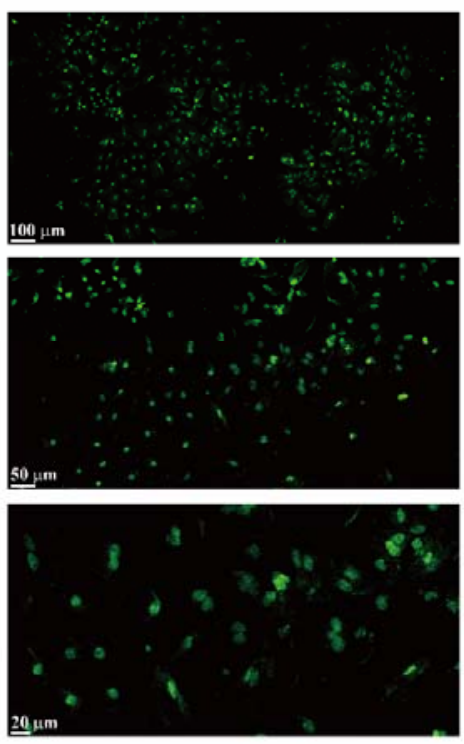

Merge
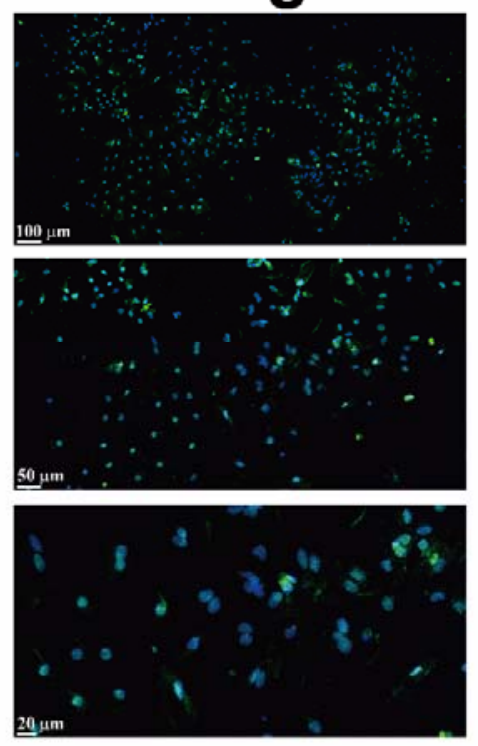

Fig. S2. Immunofluorescence images for visualization of primary neurons at 14 days in vitro. Representative images of C57BL/6 primary cortical neurons cultured for 14 days. The cell nuclei were stained with primary anti-NeuN antibody and DyLight 488-labelled secondary antibody (green) and then counterstained with DAPI (blue). The images were then merged to visualize neurons (double-stained). Three scaled (scale bars, $20 \mu \mathrm{m}, 50 \mu \mathrm{m}$ and $100 \mu \mathrm{m}$ ) images are shown. 
Fig. S3.

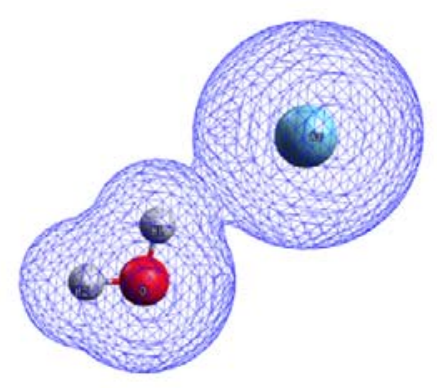

argon

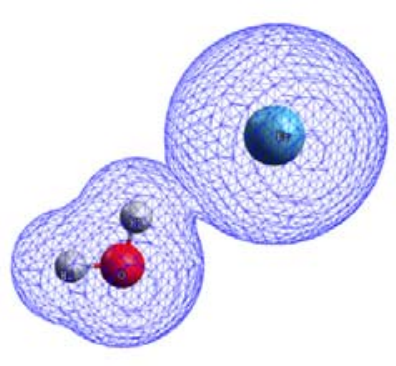

krypton

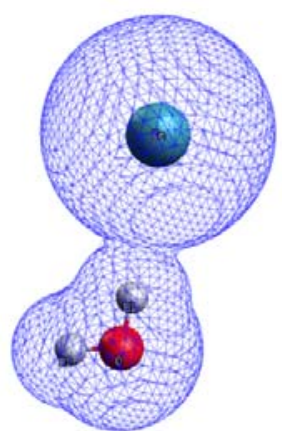

xenon

Fig. S3. Structures of inert anesthetics with water molecules. The geometries of argon, krypton and xenon combined with one water molecule are shown. The molecular structures are depicted with balls and sticks, and the van der Waals surfaces are shown with thin blue lines around the molecules. The geometries and binding energies of argon, krypton, and xenon were obtained by molecular dynamics simulations using the QZVPP basis set at coupled-cluster singles and doubles with perturbative triple correction $[\operatorname{CCSD}(\mathrm{T})]$ at the def2-QZVPP level of theory. The binding energies of helium and neon are -0.048 and $-0.090 \mathrm{kcal} / \mathrm{mol}$, respectively, which are used to plot Fig. 4A to obtain their MACs using linear regressions. ${ }^{129}$ Xenon, ${ }^{131}$ xenon, and ${ }^{134}$ xenon have identical binding energies of $-0.4177 \mathrm{kcal} / \mathrm{mol}$. 
Fig. S4.
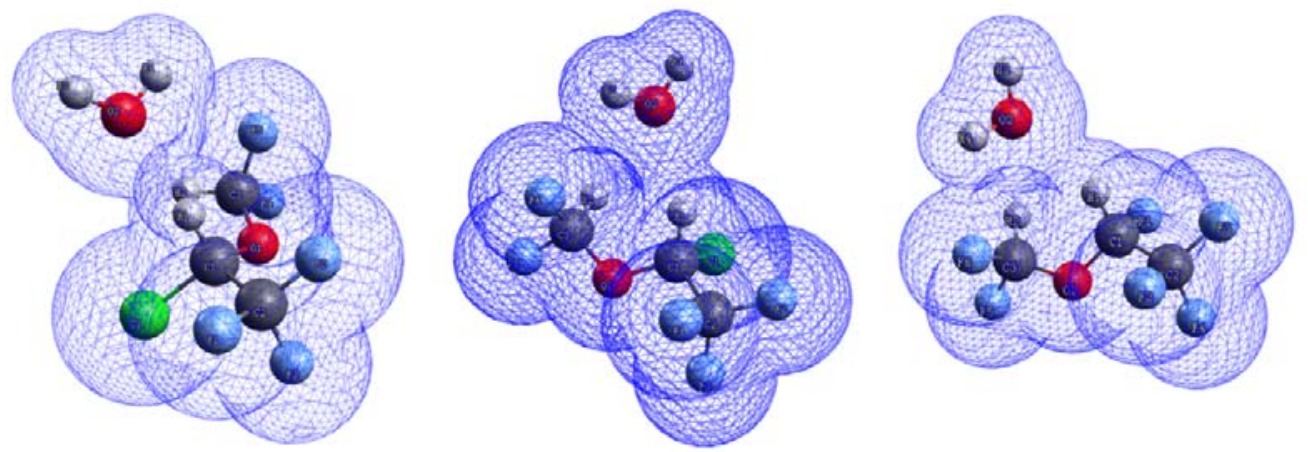

\section{S-(+)-isoflurane $R$-(-)-isoflurane}

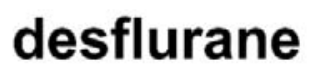

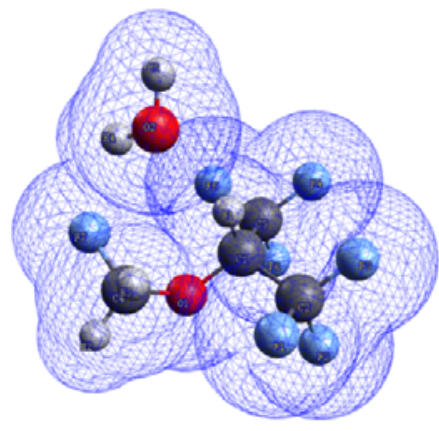

sevoflurane

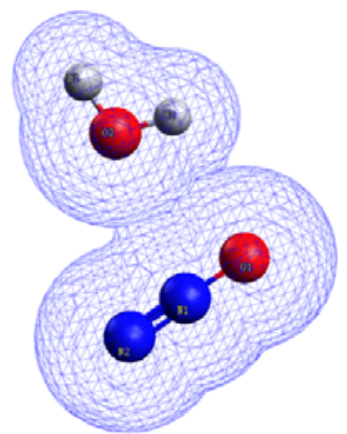

nitrous oxide

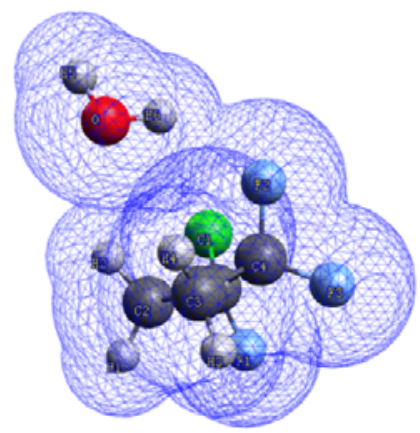

F3

Fig. S4. Structures of conventional anesthetics with water molecules. The geometries of isoflurane, desflurane, sevoflurane, nitrous oxide and F3 combining with one water molecule are shown. The molecular structures are depicted with balls and sticks, and the van der Waals surfaces are shown with thin blue lines around the molecules. The geometries and binding energies were obtained by using molecular dynamics simulations at the density functional theory (DFT) and B3LYP/def2-TZVPPD levels of theory. Note that $S$-(+)-isoflurane and $R$-(-)-isoflurane are structurally symmetrical. Because of the symmetry, the two enantiomers have the same binding energy. 
Fig. S5.

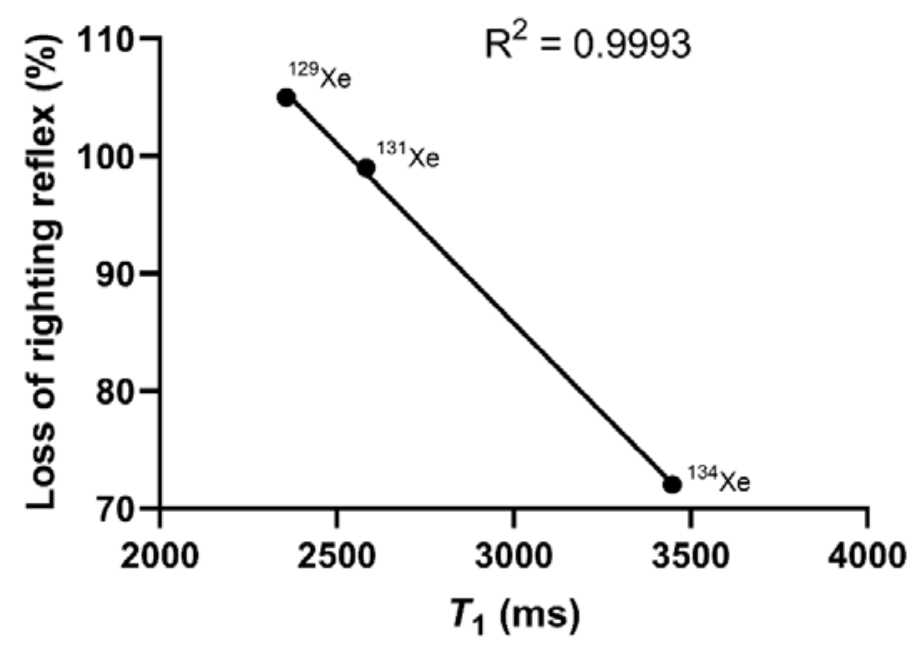

Fig. S5. Correlation of the aesthetic potencies of xenon isotopes with $\boldsymbol{T}_{\mathbf{1}}$. The data in Table 1 in the main text were used to plot this figure. 


\section{Table S1.}

Table S1. The binding energies and harmonic vibrational frequencies between conventional anesthetics and water molecules.

\begin{tabular}{lcccccccr}
\hline \multirow{2}{*}{ Volatile anesthetics } & $\begin{array}{c}\text { Binding energies } \\
(\mathrm{kcal} / \mathrm{mol})\end{array}$ & \multicolumn{7}{c}{ Harmonic vibrational frequencies $\left(\mathrm{cm}^{-1}\right)$} \\
\cline { 3 - 7 } & -2.32 & 46.185 & 56.195 & 114.054 & 144.502 & 194.409 & 614.115 \\
nitrous oxide & -6.01 & 19.997 & 48.678 & 49.274 & 70.029 & 77.811 & 120.801 & The \\
$S$-(+)-isoflurane & -6.01 & 19.997 & 48.678 & 49.274 & 70.029 & 77.811 & 120.801 & bindi \\
$R$-(-)-isoflurane & -6.71 & 25.759 & 34.1395 & 49.707 & 59.038 & 85.757 & 117.149 & ng \\
sevoflurane & -6.01 & 16.198 & 41.886 & 50.790 & 71.321 & 83.531 & 121.036 & energ \\
desflurane & -4.61 & 23.109 & 70.692 & 88.384 & 115.762 & 126.428 & 180.530 & y and \\
F3 & & & & & & & & harm
\end{tabular}

onic vibrational frequencies of one aesthetic molecule binding with one water molecule were calculated by using molecular dynamics simulations with density functional theory (DFT) and the B3LYP/def2-TZVPPD level of theory. Configurations with imaginary frequencies were excluded. For the configurations of any aesthetic with nonimaginary frequencies, only the lowest binding energy was selected to plot in Fig. 4B according to the energy minima principle. The binding energies of F6 and F8 were -0.54 and $-1.32 \mathrm{kcal} / \mathrm{mol}$, respectively, which were used to plot Fig. $4 \mathrm{~B}$ to obtain their MACs via linear regression. 


\section{References}

66. S. Kaech, G. Banker, Culturing hippocampal neurons. Nat. Protoc. 1, 2406-2415 (2006).

67. C. Zhou, C. Qi, J. Zhao, F. Wang, W. Zhang, C. Li, J. Jing, X. Kang, Z. Chai, Interleukin-1 $\beta$ inhibits voltage-gated sodium currents in a time- and dose-dependent manner in cortical neurons. Neurochem. Res. 36, 1116-1123 (2011).

68. D. Gąszowski, M. Ilczyszyn, Hydrogen bonding to xenon: A comparison with neon, argon and krypton complexes. Chem. Phys. Lett. 556, 59-64 (2013).

69. F. Neese, Software update: the ORCA program system, version 4.0. Wiley Interdiscip. Rev. Comput. Mol. Sci. 8, 1-6 (2017).

70. F. Weigend, R. Ahlrichs, Balanced basis sets of split valence, triple zeta valence and quadruple zeta valence quality for $\mathrm{H}$ to $\mathrm{Rn}$ : Design and assessment of accuracy. Phys. Chem. Chem. Phys. 7, 3297-3305 (2005).

71. M. D. Hanwell, D. E. Curtis, D. C. Lonie, T. Vandermeersch, E. Zurek, G. R. Hutchison, Avogadro: an advanced semantic chemical editor, visualization, and analysis platform. $J$. Cheminform. 4, 17 (2012).

72. M. Hosseini-Sharifabad, J. R. Nyengaard, Design-based estimation of neuronal number and individual neuronal volume in the rat hippocampus. J. Neurosci. Methods 162, 206-214 (2007).

73. F. Sartori, A. S. Hafner, A. Karimi, A. Nold, Y. Fonkeu, E. M. Schuman, T. Tchumatchenko, Statistical laws of protein motion in neuronal dendritic trees. Cell Rep. 33, 108391 (2020).

74. J. M. Sonner, J. F. Antognini, R. C. Dutton, P. Flood, A. T. Gray, R. A. Harris, G. E. Homanics, J. Kendig, B. Orser, D. E. Raines, J. Trudell, B. Vissel, E. I. Eger $\square$, Inhaled anesthetics and immobility: Mechanisms, mysteries, and minimum alveolar anesthetic concentration. Anesth. Analg. 97, 718-740 (2003).

75. D. D. Koblin, Z. Fang, E. I. Eger $\square$, M. J. Laster, D. Gong, P. Ionescu, M. J. Halsey, J. R. Trudell, Minimum alveolar concentrations of noble gases, nitrogen, and sulfur hexafluoride in rats. Anesth. Analg. 87, 419-424 (1998).

76. C. T. Gonsowski, E. I. Eger $\square$, Nitrous oxide minimum alveolar anesthetic concentration in rats is greater than previously reported. Anesth. Analg. 79, 710-712 (1994).

77. K. Solt, E. I. Eger $\square$, D. E. Raines, Differential modulation of human N-methyl-D-aspartate receptors by structurally diverse general anesthetics. Anesth. Analg. 102, 1407-1411 (2006).

78. R.Sander, Compilation of Henry's law constants (version 4.0) for water as solvent. Atmos. Chem. Phys. 15, 4399-4981 (2015).

79. R. L. Davisson, G. Yang, T. G. Beltz, M. D. Cassell, A. K. Johnson, C. D. Sigmund, The brain renin-angiotensin system contributes to the hypertension in mice containing both the human renin and human angiotensinogen transgenes. Cir. Res. 83, 1047-1058 (1998).

80. C. Perrin, C. Knauf, R. Burcelin, Intracerebroventricular infusion of glucose, insulin, and the adenosine monophosphate-activated kinase activator, 5-aminoimidazole-4-carboxamide-1- $\beta$ D-ribofuranoside, controls muscle glycogen synthesis. Endocrinology 145, 4025-4033 (2004). 


\section{Figures}
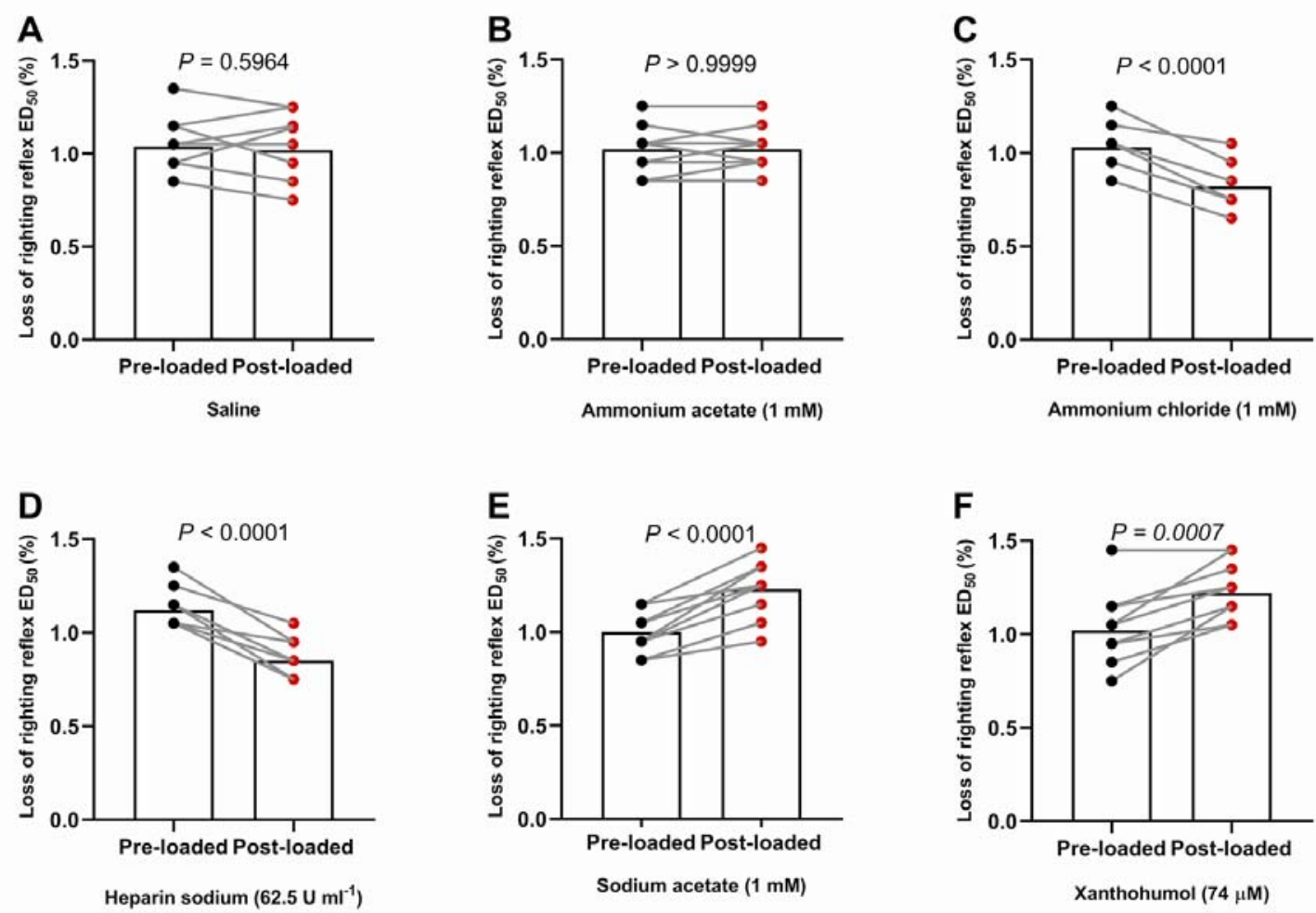

Fig. 1. Effects of weak acids and weak bases on the LORR ED $_{50}$ of sevoflurane in mice. Saline and weak acids and bases were intracerebroventricularly injected into mice. A, $0.9 \% \mathrm{NaCl}$ did not affect the LORR $\mathrm{ED}_{50}$ (pre-SD, 0.15, post-SD, 0.19; and $95 \%$ CI, 0.93 to $1.15 \%$ versus 0.88 to $1.15 \%$ ). B, Ammonium acetate had no effect (pre-SD, 0.13, post-SD, 0.13 ; and 95\% CI, 0.93 to $1.11 \%$ versus 0.94 to $1.10 \%$ ). Weak acids reduced the LORR $\mathrm{ED}_{50}$ values: $\mathbf{C}$, ammonium chloride (pre-SD, 0.11, post-SD, 0.12 ; and $95 \% \mathrm{CI}, 0.95$ to $1.11 \%$ versus 0.74 to $0.90 \%$ ) and $\mathbf{D}$, heparin sodium (pre-SD, 0.11, post-SD, 0.11; and 95\% CI, 1.04 to $1.20 \%$ versus 0.77 to $0.92 \%$ ). Weak bases increased the LORR $\mathrm{ED}_{50}$ values: $\mathbf{E}$, sodium acetate (pre-SD, 0.15 , post-SD, 0.13 ; and $95 \% \mathrm{CI}, 1.11$ to $1.32 \%$ versus 0.92 to $1.10 \%$ ) and $\mathbf{F}$, xanthohumol (pre-SD, 0.18, post-SD, 0.16; and 95\% CI, 0.88 to $1.16 \%$ versus 1.11 to $1.33 \%)$. The injection volume was $2 \mu$. Mean $(n=10$ mice), two-tailed paired $t$-test. The LORR $\mathrm{ED}_{50}$ is presented as the sevoflurane concentration (\%). LORR ED $\mathrm{ED}_{50}$ denotes the $50 \%$ effective dose for the loss of righting reflex. 

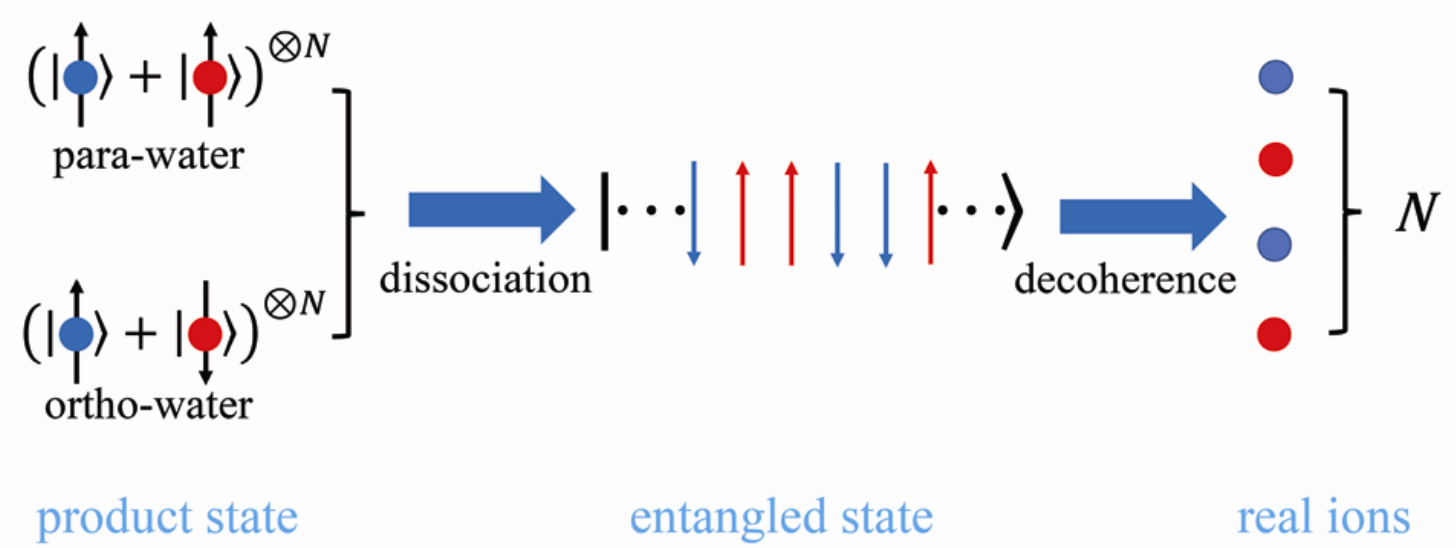

\section{entangled state}

real ions

Fig. 2. Schematic illustration of Ising model to describe the entanglemnts of the hydronium and hydroxide ions. A symmetric state (left) is a product state of the nuclear spins of hydrogen nuclei (within water molecules) which spin-up and -down. An entangled state of hydronium and hydroxide ions (middle) is shown where the spins are within a 1-d Ising chain. A collapsed state (right) is a state of the real hydronium and hydroxide ions. Red and blue denote different hydrogen nuclei in water molecucles (left) and represent different ions (middle and right). Arrows denote spin directions, and $\bullet$ the ions. 

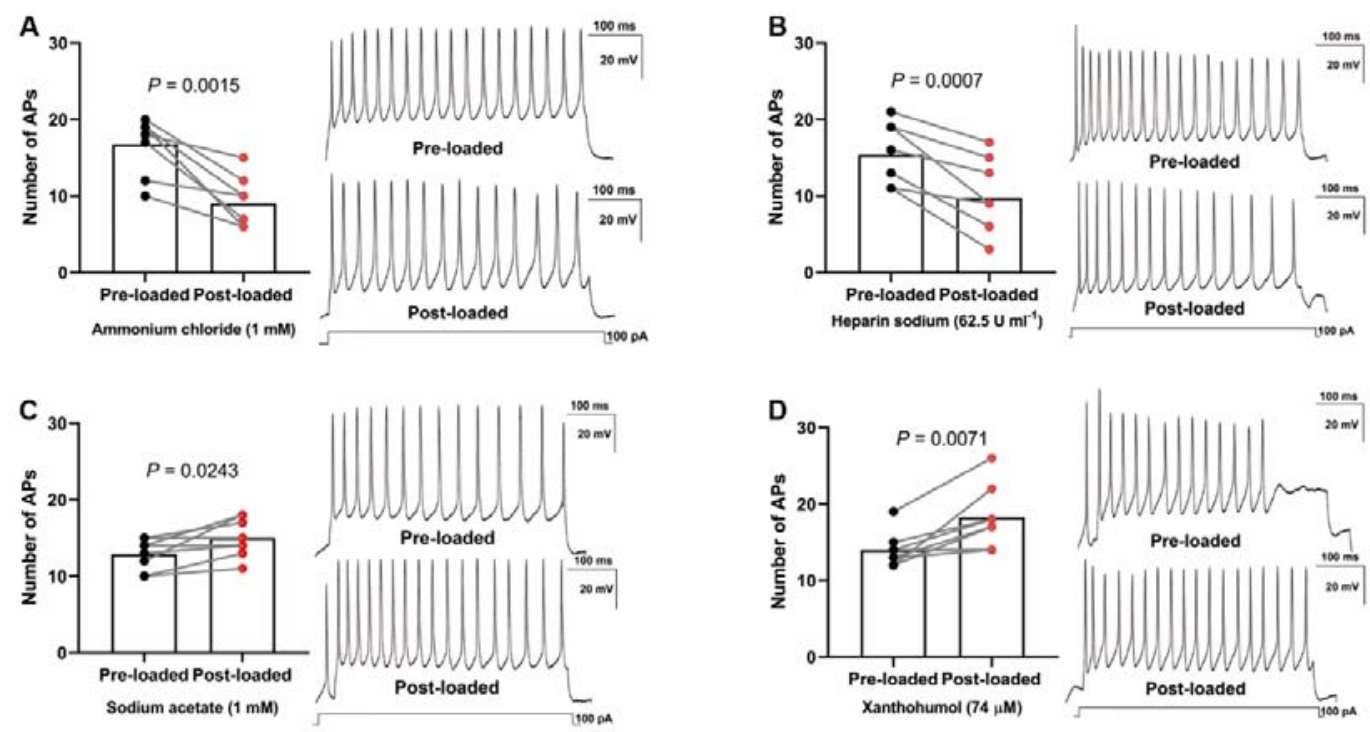

Fig. 3. Effects of weak acids and bases on the neuronal spiking rate. Weak acids decreased the spiking rate: A, ammonium chloride (pre-SD, 3.69, and post-SD, 3.34; and $95 \%$ CI, 13.66 to 19.84 versus 6.209 to 11.79 ) and $\mathbf{B}$, heparin sodium (pre-SD, 3.93, post-SD, 4.86; and 95\% CI, 12.09 to 18.66 versus 5.685 to 13.82). Weak bases increased the spiking rate: $\mathbf{C}$, sodium acetate (pre-SD, 2.03, post-SD, 2.51; and 95\% CI, 12.09 to 18.66 versus 5.685 to 13.82 ) and $\mathbf{D}$, xanthohumol (pre-SD, 2.27, post-SD, 4.03; and $95 \%$ CI, 12.10 to 15.90 versus 14.88 to 21.62 ). The insets (right) are the representative recordings of the action potential. In each group, a two-tailed paired $t$ test was used to compare the spiking rate. $n=8$ cells. AP denotes action potential. The spiking rate is the number of action potentials in $500 \mathrm{~ms}$. 

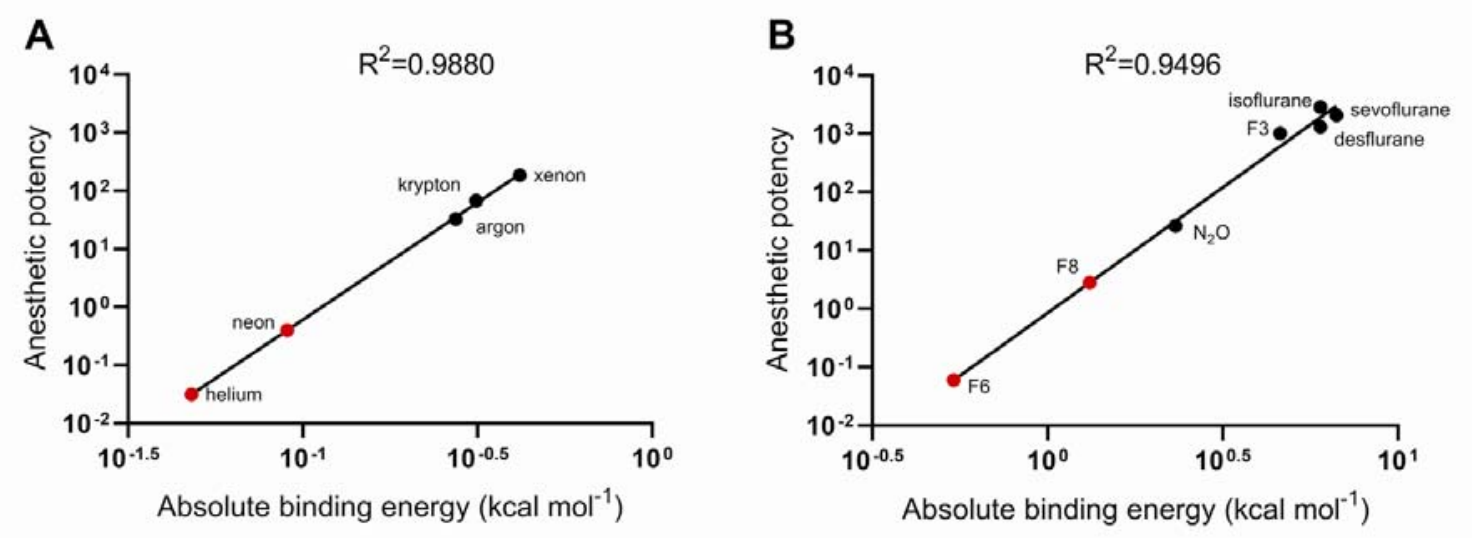

Fig. 4. Relationship of the binding energies of the inhaled anesthetics with their anesthetic potencies. The data are plotted as potencies, defined as reciprocals of the aqueous $50 \%$ effective concentrations $(\mathrm{M})$ in rats (supplement text). Because the results of different basis sets cannot be compared, the data are presented in two panels. A, Inert gases. B, Conventional anesthetics and F3. The logarithms of the aqueous 50\% effective concentrations for the two classes of inhaled anesthetics correlate well with the logarithms of the absolute values of their binding energies, showing as large values of $\mathrm{R}^{2}$. The binding energies of helium and neon (red dots) are plotted in panel $\mathbf{A}$, and F6 and F8 (red dots) in panel $\mathbf{B}$, to determine their anesthetic potencies by linear regression. 
Tables

Table 1. Comparisons of xenon isotopic potencies with their $\boldsymbol{f}$ ratios.

\begin{tabular}{ccccc}
\hline Isotope & LORR ED $_{50}(\%)^{\mathrm{a}}$ & $T_{1}^{\mathrm{H}}(\mathrm{ms})^{\mathrm{b}}$ & $\begin{array}{c}\text { LORR ED }_{50} \\
\text { Ratio }^{\mathrm{c}}\end{array}$ & $f$ Ratio $^{\mathrm{d}}$ \\
\hline${ }^{129}$ xenon & 105 & $2357(144)$ & 0.69 & 0.68 \\
${ }^{131}$ xenon & 99 & $2583(195)$ & 0.73 & 0.75 \\
${ }^{134}$ xenon & 72 & $3448(202)$ & 1 & 1 \\
\hline
\end{tabular}

${ }^{\mathrm{a}}$ Cited from our previous study (3).

${ }^{\mathrm{b}}$ Acquired by nuclear magnetic resonance imaging. Mean (SD), $n=4$ samples for each isotope. The isotopes in this study were the same batches used in our previous experiment (3) to test the LORR $\mathrm{ED}_{50}$ in mice. No statistical analysis was performed to compare the differences between isotopes.

${ }^{\mathrm{c} C}$ Calculated using $\frac{\text { LORR ED }_{50}}{{ }^{134} \mathrm{Xe} \mathrm{LORR} \mathrm{ED}_{50}}$.

${ }^{\mathrm{d}}$ Calculated using $\frac{T_{1}^{\mathrm{H}}}{{ }^{134} \mathrm{Xe} T_{1}^{\mathrm{H}}}$.

Different animal species may have different MAC values. For a given animal species, different laboratories may obtain different MAC values derived from different experimental paradigms involving different nociceptive stimuli. As such, in this study the MACs of inhaled anaesthetics were cited from one laboratory (Department of Anaesthesia and Perioperative Care, University of California, San Francisco, CA, USA) in one animal species, Sprague-Dawley rats. If discrepancy appeared, the most recently published data were cited. Finally, the MACs in SpragueDawley rats to inert gases (argon, krypton, and xenon) ${ }^{60}$, nitrous oxide ${ }^{61}$, conventional anaesthetics (isoflurane, desflurane, and sevoflurane) ${ }^{62}$, and F3 (1-chloro-1,2,2trifluorocyclobutane) $)^{9}$ were cited. The MACs in partial pressure were converted into aqueous $\mathrm{ED}_{50}$ values at $37 \square$ using Henry's law ${ }^{63}$ to plot Fig. 3 in the main text.

\section{References}

1. Ton, H. T., Phan, T. X., Abramyan, A. M., Shi, L. \& Ahern, G. P. Identification of a putative binding site critical for general anesthetic activation of TRPA1. Proc. Natl. Acad. Sci. U. S. A. 114, 3762-3767 (2017).

2. Kelz, M. B. \& Mashour, G. A. The Biology of General Anesthesia from Paramecium to Primate. Curr. Biol. 29, R1199-R1210 (2019).

3. Hameroff, S. Anesthesia, consciousness and hydrophobic pockets-a unitary quantum hypothesis of anesthetic action. Toxicol. Lett. 100-101, 31-39 (1998).

4. Sonner, J. M. \& Cantor, R. S. Molecular Mechanisms of Drug Action: An Emerging View. Annu. Rev. Biophys. 42, 143-167 (2013).

5. Kent, D. W., Halsey, M. J., Eger, E. I. \& Kent, B. Isoflurane anesthesia and pressure antagonism in mice. Anesth. Analg. 56, 97-101 (1977).

6. Smith, E. B. et al. Species variation and the mechanism of pressure-anaesthetic interactions. Nature 311, 56-57 (1984).

7. JOHNSON, S. M. \& MILLER, K. W. Antagonism of Pressure and Anaesthesia. Nature 228, 75-76 (1970).

8. Eger, E. I. et al. Minimum Alveolar Anesthetic Concentration Values for the Enantiomers of Isoflurane Differ Minimally. Anesth. Analg. 85, 188-192 (1997). 
9. Koblin, D. D. et al. Polyhalogenated and perfluorinated compounds that disobey the Meyer- Overton hypothesis. Anesth. Analg. 79, 1043-1048 (1994).

10. Li, N. et al. Nuclear Spin Attenuates the Anesthetic Potency of Xenon Isotopes in Mice: Implications for the Mechanisms of Anesthesia and Consciousness. Anesthesiology 129, 271-277 (2018).

11. Hameroff, S. R. The Entwined Mysteries of Anesthesia and Consciousness. Anesthesiology 105, 400-412 (2006).

12. Turin, L., Skoulakis, E. M. C. \& Horsfield, A. P. Electron spin changes during general anesthesia in Drosophila. Proc. Natl. Acad. Sci. U. S. A. 111, (2014).

13. Craddock, T. J. A., Hameroff, S. R., T. Ayoub, A., Klobukowski, M. \& Tuszynski, J. A. Anesthetics Act in Quantum Channels in Brain Microtubules to Prevent Consciousness. Curr. Top. Med. Chem. 15, 523-533 (2015).

14. Fisher, M. P. A. Quantum cognition: The possibility of processing with nuclear spins in the brain. Ann. Phys. (N. Y). 362, 593-602 (2015).

15. Chen, R., Li, N., Qian, H., Zhao, R. \& Zhang, S. Experimental evidence refuting the assumption of phosphorus-31 nuclear-spin entanglement-mediated consciousness. J. Integr. Neurosci. 19, 595 (2020).

16. Kathagen, N. \& Prehm, P. Regulation of intracellular pH by glycosaminoglycans. J. Cell. Physiol. 228, 2071-2075 (2013).

17. Rudick, R. A., Zirretta, D. K. \& Herndon, R. M. Clearance of albumin from mouse subarachnoid space: a measure of CSF bulk flow. J. Neurosci. Methods 6, 253-259 (1982).

18. De Martini, F. Amplification of Quantum Entanglement. Phys. Rev. Lett. 81, 2842-2845 (1998).

19. Pang, S., Dressel, J. \& Brun, T. A. Entanglement-Assisted Weak Value Amplification. Phys. Rev. Lett. 113, 030401 (2014).

20. Kattnig, D. R. et al. Chemical amplification of magnetic field effects relevant to avian magnetoreception. Nat. Chem. 8, 384-391 (2016).

21. Chatzidimitriou-Dreismann, C. A., Abdul Redah, T., Streffer, R. M. F. F. \& Mayers, J. Anomalous Deep Inelastic Neutron Scattering from Liquid $<$ math display="inline" $>\quad\langle$ mrow $>\quad<$ msub $\quad<$ mrow $>\quad$ mi mathvariant="normal" $\rangle \mathrm{H}\langle/ \mathrm{mi}\rangle\langle$ mrow $\rangle\langle$ mrow $\rangle\langle$ mn $\rangle 2\langle/$ mn $\rangle\langle$ mrow $\rangle$ $<$ msub $><$ /mrow $><$ math $>$ O- <math display="inline" $><$ mrow $><$ msub $>$ $<$ mrow $><$ mi mathvariant=. Phys. Rev. Lett. 79, 2839-2842 (1997).

22. Chatzidimitriou-Dreismann, C. A. \& Mayers, J. Anomalous neutron and Raman scattering due to EPR correlated protons in liquid water. Phys. B Condens. Matter 226, 231-233 (1996).

23. Soper, A. K. \& Benmore, C. J. Quantum Differences between Heavy and Light Water. Phys. Rev. Lett. 101, 065502 (2008).

24. Weingärtner, H. \& Chatzidimttriou-Dreismann, C. A. Anomalous H+ and D+ conductance in H2O-D2O mixtures. Nature 346, 548-550 (1990).

25. $\mathrm{Hu}, \mathrm{H} . \& \mathrm{Wu}, \mathrm{M}$. Evidence of Non-Local Physical, Chemical and Biological Effects Supports Quantum Brain. NeuroQuantology 4, 291-306 (2007).

26. Geissler, P. L. Autoionization in Liquid Water. Science (80-. ). 291, 2121-2124 (2001).

27. Hassanali, A., Prakash, M. K., Eshet, H. \& Parrinello, M. On the recombination of hydronium and hydroxide ions in water. Proc. Natl. Acad. Sci. U. S. A. 108, 20410-20415 (2011).

28. Motlagh, H. N., Wrabl, J. O., Li, J. \& Hilser, V. J. The ensemble nature of 
allostery. Nature 508, 331-339 (2014).

29. Zangi, R. \& Engberts, J. B. F. N. Physisorption of Hydroxide Ions from Aqueous Solution to a Hydrophobic Surface. J. Am. Chem. Soc. 127, 22722276 (2005).

30. Kudin, K. N. \& Car, R. Why Are Water-Hydrophobic Interfaces Charged? J. Am. Chem. Soc. 130, 3915-3919 (2008).

31. Vu, T. H. \& Shultz, M. J. Vibrating hydroxide in hydrophobic solution: The ion to keep an eye on. Chem. Phys. Lett. 572, 13-15 (2013).

32. Liu, Y. \& Dilger, J. P. Application of the one- and two-dimensional Ising models to studies of cooperativity between ion channels. Biophys. J. 64, 26-35 (1993).

33. Traynelis, S. F. \& Cull-Candy, S. G. Proton inhibition of N-methyl-D-aspartate receptors in cerebellar neurons. Nature 345, 347-350 (1990).

34. Kaila, K., Paalasmaa, P., Taira, T. \& Voipio, J. pH transients due to monosynaptic activation of GABAA receptors in rat hippocampal slices. Neuroreport 3, 105-108 (1992).

35. Stengle, T. R., Reo, N. V. \& Williamson, K. L. Nuclear magnetic relaxation of xenon-131 in solution. The influence of solvent electric moment and dynamics on solute relaxation. J. Phys. Chem. 88, 3225-3228 (1984).

36. Holzmüller, P., Moser, E., Werba, A., Markis, E. M. \& Gomiscek, G. In vitro NMR investigation of controlled single and repeated isoflurane anesthesia. Magn. Reson. Imaging 10, 393-400 (1992).

37. Sutradhar, D., Zeegers-Huyskens, T. \& Chandra, A. K. A theoretical investigation on the conformation and the interaction of CHF2OCF2CHF2 (desflurane II) with one water molecule. J. Mol. Model. 19, 5045-5052 (2013).

38. Sutradhar, D., Zeegers-Huyskens, T. \& Chandra, A. K. Strong Hyperconjugative Interactions in Isolated and Water Complexes of Desflurane: A Theoretical Investigation. J. Phys. Chem. A 117, 8545-8554 (2013).

39. Dimitrov, I. E., Reddy, R. \& Leigh, J. S. Intermolecular Dipole-Dipole Relaxation of 129Xe Dissolved in Water. J. Magn. Reson. 145, 302-306 (2000).

40. Dickinson, R., White, I., Lieb, W. R. \& Franks, N. P. Stereoselective Loss of Righting Reflex in Rats by Isoflurane. Anesthesiology 93, 837-843 (2000).

41. Eckenhoff, M. F., Chan, K. \& Eckenhoff, R. G. Multiple Specific Binding Targets for Inhaled Anesthetics in the Mammalian Brain. J. Pharmacol. Exp. Ther. 300, 172-179 (2002).

42. Schwegler, E., Galli, G., Gygi, F. \& Hood, R. Q. Dissociation of water under pressure. Phys. Rev. Lett. 87, 265501 (2001).

43. Liu, B., Gao, Y., Han, Y., Ma, Y. \& Gao, C. In situ electrical conductivity measurements of $\mathrm{H} 2 \mathrm{O}$ under static pressure up to $28 \mathrm{GPa}$. Phys. Lett. Sect. A Gen. At. Solid State Phys. 380, 2979-2983 (2016).

44. Bonnet, U., Bingmann, D., Speckmann, E.-J. \& Wiemann, M. Small intraneuronal acidification via short-chain monocarboxylates: First evidence of an inhibitory action on over-excited human neocortical neurons. Life Sci. 204, 65-70 (2018).

45. Plante, D. T. et al. Gray Matter-Specific Changes in Brain Bioenergetics after Acute Sleep Deprivation: A 31P Magnetic Resonance Spectroscopy Study at 4 Tesla. Sleep 37, 1919-1927 (2014).

46. Kaech, S. \& Banker, G. Culturing hippocampal neurons. Nat. Protoc. 1, 24062415 (2006). 
47. Zhou, C. et al. Interleukin-1 $\beta$ Inhibits Voltage-Gated Sodium Currents in a Time- and Dose-Dependent Manner in Cortical Neurons. Neurochem. Res. 36, 1116-1123 (2011).

48. Gąszowski, D. \& Ilczyszyn, M. Hydrogen bonding to xenon: A comparison with neon, argon and krypton complexes. Chem. Phys. Lett. 556, 59-64 (2013).

49. Neese, F. Software update: the ORCA program system, version 4.0. Wiley Interdiscip. Rev. Comput. Mol. Sci. 8, 1-6 (2018).

50. Weigend, F. \& Ahlrichs, R. Balanced basis sets of split valence, triple zeta valence and quadruple zeta valence quality for $\mathrm{H}$ to $\mathrm{Rn}$ : Design and assessment of accuracy. Phys. Chem. Chem. Phys. 7, 3297 (2005).

51. Hanwell, M. D. et al. Avogadro: an advanced semantic chemical editor, visualization, and analysis platform. J. Cheminform. 4, 17 (2012).

52. Hosseini-Sharifabad, M. \& Nyengaard, J. R. Design-based estimation of neuronal number and individual neuronal volume in the rat hippocampus. $J$. Neurosci. Methods 162, 206-214 (2007).

53. Sartori, F. et al. Statistical Laws of Protein Motion in Neuronal Dendritic Trees. Cell Rep. 33, 108391 (2020).

54. Teng, B. \& Sy, H. K. Spin correlations in the Ising chains. Solid State Commun. 130, 193-197 (2004).

55. Teng, B. et al. Comparison between the nearest and the next-nearest neighbor site-spin interactions in the Ising model. Solid State Commun. 124, 347-351 (2002).

56. Self-dissociation and protonic charge transport in water and. Proc. R. Soc. London. Ser. A. Math. Phys. Sci. 247, 505-533 (1958).

57. Swift, M. W., Van de Walle, C. G. \& Fisher, M. P. A. Posner molecules: from atomic structure to nuclear spins. Phys. Chem. Chem. Phys. 20, 12373-12380 (2018).

58. CHANG, D. C., HAZLEWOOD, C. F., NICHOLS, B. L. \& RORSCHACH, H. E. Spin Echo Studies on Cellular Water. Nature 235, 170-171 (1972).

59. Sonner, J. M. et al. Inhaled Anesthetics and Immobility: Mechanisms, Mysteries, and Minimum Alveolar Anesthetic Concentration. Anesth. Analg. 97, 718-740 (2003).

60. Koblin, D. D. et al. Minimum Alveolar Concentrations of Noble Gases, Nitrogen, and Sulfur Hexafluoride in Rats. Anesth. Analg. 87, 419-424 (1998).

61. Gonsowski, C. T. \& Eger, E. I. Nitrous oxide minimum alveolar anesthetic concentration in rats is greater than previously reported. Anesth. Analg. 79, 710-712 (1994).

62. Solt, K., Eger, E. I. \& Raines, D. E. Differential Modulation of Human NMethyl-d-Aspartate Receptors by Structurally Diverse General Anesthetics. Anesth. Analg. 102, 1407-1411 (2006).

63. Sander, R. Compilation of Henry's law constants (version 4.0) for water as solvent. Atmos. Chem. Phys. 15, 4399-4981 (2015). 